Supporting Information

for

\title{
Precisely Shaped Self-Adjuvanting Peptide Vaccines with Enhanced Immune Responses for HPV-Associated Cancer Therapy
}

\author{
Yanqiu Song, ${ }^{1}$ Qi Su, ${ }^{2}$ Huijuan Song, ${ }^{2}$ Xiaoguang Shi, ${ }^{1}$ Mingming Li,${ }^{1}$ Na Song, ${ }^{1}$ \\ Shaofeng Lou, ${ }^{1}$ Weiwei Wang, ${ }^{2 *}$ and Zhilin $\mathrm{Yu}^{1 *}$
}

${ }^{1}$ Key Laboratory of Functional Polymer Materials, Ministry of Education, State Key Laboratory of Medicinal Chemical Biology, Institute of Polymer Chemistry, College of Chemistry, Nankai University, Weijin Road 94, Tianjin 300071, China

${ }^{2}$ Tianjin Key Laboratory of Biomaterial Research, Institute of Biomedical Engineering, Chinese Academy of Medical Sciences and Peking Union Medical College, Baidi Road 236, Tianjin 300192, China 


\section{Materials and methods}

\section{Materials}

2-Chlorotrityl chloride resin (loading density : $0.5 \mathrm{mmol} / \mathrm{g}$ ) and Rink amide resin (loading density : $0.56 \mathrm{mmol} / \mathrm{g}$ ) were purchased from ApexBio Technology Co., Ltd. All amino acids, N,N'-diisopropylethylamine (DIEA), hexafluorophosphate azabenzotriazole tetramethyl uronium (HATU), and 5-carboxyfluorescein (FAM) used to synthesize peptides were purchased from Bide Pharmatech Co., Ltd. Trifluoroacetic acid (TFA) and triisopropylsilane were supplied by Meryer Chemical Technology Co. Ltd. Dichloromethane $\left(\mathrm{CH}_{2} \mathrm{Cl}_{2}\right)$, methanol $\left(\mathrm{CH}_{3} \mathrm{OH}\right)$, and $\mathrm{N}$, N'-dimethylformamide (DMF) were provided by Tianjin Concord Technology Co., Ltd. Piperidine was obtained from Sinopharm Chemical Reagent Co., Ltd. Thioflavin T (ThT) and 1, 3Diphenylisobenzofuran (DPBF) were purchased from J\&K Scientific Ltd. 3-(4, 5Dimethylthiazol-2-yl)-2, 5-diphenyltetrazolium bromide (MTT) and 4', 6-diamidino2-phenylindole (DAPI) were obtained from Sigma-Aldrich. Lysotracker Green DND26 was supplied by Dalian Meilun Biotech Co., Ltd. Roswell Park Memorial Institute (RPMI) 1640 medium, Dulbecco's modified Eagle's medium (DMEM), penicillin/streptomycin solution (PS), trypsin, fetalbovine serum (FBS), and $4 \%$ paraformaldehyde were purchased from Gibco (CA, America). Anti-PD-1 antibody was purchased from Bio X Cell Inc. All other antibodies used in the experiment and immune-promoting cytokines (IFN- $\gamma$, IL-2 and TNF- $\alpha$ ) ELISA kit were purchased from BioLegend. All reagents were analytical grade. Ultrapure water was produced by Arium Pro Ultrapure water systems (Sartorius, 18.2 M $\Omega$ ). 
The DC2.4 cell line and TC-1 cells were purchased from Shanghai Huzhen Bio. Tech. Co., Ltd. and cultured according to the instructions from manufacturer. Female C57BL/6J (6-8 weeks) mice used in this study were purchased from Beijing Vital River Lab. Animal Tech. Co. The animal experiments were approved by Center of Tianjin Animal Experiment Ethics Committee and Authority for Animal Protection. MSCs were collected from marrow cavities of the femurs and tibias of $\mathrm{C} 57 \mathrm{BL} / 6 \mathrm{~J}$ mice and then cultured in RPMI 1640 medium containing 20 ng/mL Granulocyte-macrophage Colony Stimulating Factor (GM-CSF), 10 ng/mL Interleukin-4 (IL-4), $5 \mathrm{ng} / \mathrm{mL} \beta$ mercaptoethanol, $100 \mathrm{mg} / \mathrm{mL}$ streptomycin, and $100 \mathrm{IU} / \mathrm{mL}$ penicillin for 5 days to induce the differentiation of MSCs to BMDCs.

Syntheses of peptides AmpF, PF, E749-57, E744-57, AmpFE749-57, AmpFE744-57, PFE749-57, and PFE744-57

Peptide AmpF, PF, E749-57, E744-57, AmpFE749-57, AmpFE744-57, PFE749-57, and PFE74457 were synthesized via standard Fmoc solid-phase peptide synthesis (SPPS) method. While peptides AmpF and PF were synthesized on 2-chlorotrityl chloride resin, peptides E749-57, E744-57, AmpFE749-57, AmpFE744-57, $\mathrm{PFE}_{49-57}$, and $\mathrm{PFE}_{44-57}$ were synthesized using Rink amide resin. In the cases of 2-chlorotrityl chloride resin syntheses, 2-chlorotrityl chloride resin was swelled in anhydrous $\mathrm{CH}_{2} \mathrm{Cl}_{2}$ for $30 \mathrm{~min}$. Then a mixture of Fmoc-Phe-OH (4 eq. relative to resin), DIEA (6 eq.) in anhydrous $\mathrm{CH}_{2} \mathrm{Cl}_{2}$ was added to 2-chlorotrityl chloride resin. After $1 \mathrm{~h}, \mathrm{CH}_{3} \mathrm{OH}$ was added and shaken for another $30 \mathrm{~min}$ to terminate the resin sealing process. The sealed resin was 
successively washed by DMF and $\mathrm{CH}_{2} \mathrm{Cl}_{2}$. In the cases of attaching the left amino acids on 2-chlorotrityl chloride resin or attaching all amino acids on Rink amide resin, amino acid coupling reactions were carried out by dissolving a mixture of amino acid / HBTU / DIEA ( $4: 3.95: 6$ relative to the resin) in DMF. Fmoc deprotection was performed in the presence of piperidine in DMF (30\%) solution for 30 min. Peptides AmpF and PF were cleaved from the resin using a cocktail of $50 \%$ trifluoroacetic acid in $\mathrm{CH}_{2} \mathrm{Cl}_{2}$ for 1 h. Peptides E749-57, E744-57, AmpFE749-57, AmpFE744-57, PFE749-57, and PFE744-57 were cleaved from the resin using a cocktail of $95 \%$ TFA, $2.5 \%$ triisopropyl silane, and $2.5 \%$ $\mathrm{H}_{2} \mathrm{O}$ for $3 \mathrm{~h}$. The peptide solution was concentrated by rotary evaporation and precipitated by cold diethyl ether three times to obtain the crude peptide. The crude peptide was further purified by preparative reversed phase high performance liquid chromatography (RP-HPLC) with the gradient from "5 \% acetonitrile+ $95 \%$ water" to “95\% acetonitrile+5\% water" as eluting solvents in a flow rate of $15 \mathrm{~mL} / \mathrm{min}$. All the structure and purity of peptides were characterized by ultra performance liquid chromatography (UPLC) -mass spectroscopy (MS) (Waters, ACQUITY system) experiments.

Syntheses of FAM-labeled peptides AmpF-FAM, PF-FAM, E749-57-FAM, and E74457-FAM

FAM-labeled peptides AmpF-FAM, PF-FAM, E749-57-FAM, and E744-57-FAM were synthesized via standard SPPS method. The pre-prepared 2-chlorotrityl chloride resin (AmpF, PF, E749-57, and E744-57) were swelled in $\mathrm{CH}_{2} \mathrm{Cl}_{2}$ for 30 min. Then a mixture of 
5-Carboxyfluorescein(5-FAM-COOH) (4 eq. relative to resin), DIEA (6 eq.) and HBTU (3.95 eq.) in DMF was added to the swelled resin and shaked for 2 hours in the dark. All the peptides were cleaved from the resin using a cocktail of $50 \%$ trifluoroacetic acid in $\mathrm{CH}_{2} \mathrm{Cl}_{2}$ for $1 \mathrm{~h}$. After removing the organic solvent and precipitating by cold diethyl ether, the collected crude product was further purified by RP-HPLC. The FAM-labeled peptides AmpF-FAM, PF-FAM, E749-57-FAM, and E74457-FAM were integrated into peptide treatments with a percentage of $5 \%$ to the total peptide concentration to provide fluorescence signals. 


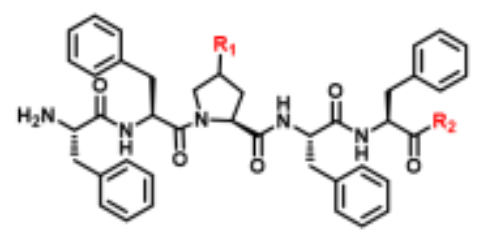

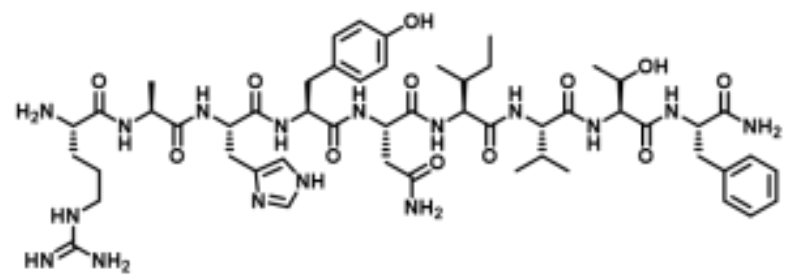

RAHYNIVTF (E7 $\left.{ }_{49-57}\right)$

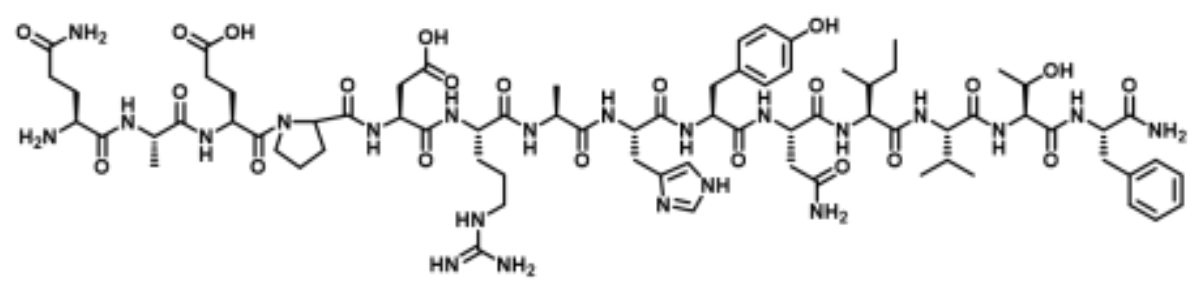

QAEPDRAHYNIVTF (E7 44-57 $)$

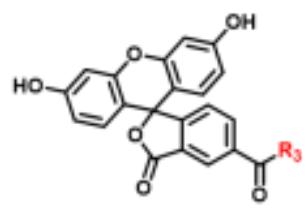

\begin{tabular}{|c|c|c|}
\hline AmpF & $\mathrm{R}_{1}=-\mathrm{NH}_{2}$ & $\mathrm{R}_{2}=-\mathrm{OH}$ \\
\hline $\mathrm{AmpFE7}_{49-57}$ & $\mathrm{R}_{1}=-\mathrm{NH}_{2}$ & $R_{2}=E 7_{49-57}$ \\
\hline AmpFE7 $_{44-57}$ & $\mathrm{R}_{1}=-\mathrm{NH}_{2}$ & $\mathbf{R}_{2}=E 7_{44-57}$ \\
\hline PF & $R_{1}=-H$ & $\mathbf{R}_{2}=-\mathrm{OH}$ \\
\hline $\mathrm{PFE7}_{49-57}$ & $R_{1}=-H$ & $R_{2}=E 7_{49-57}$ \\
\hline PFE7 $_{44-57}$ & $\mathrm{R}_{1}=-\mathrm{H}$ & $R_{2}=E 7_{44-57}$ \\
\hline AmpF-FAM & $\mathbf{R}_{3}=\mathrm{AmpF}$ & \\
\hline PF-FAM & $\mathbf{R}_{3}=\mathrm{PF}$ & \\
\hline$E 7_{49-57}-\mathrm{FAM}$ & $R_{3}=E 7_{49-57}$ & \\
\hline$E 7_{44-57}$-FAM & $R_{3}=E 7_{44-57}$ & \\
\hline
\end{tabular}

Figure S1. Chemical structures of pentapeptides AmpF and PF, antigen peptides E74957 and E744-57, antigen epitope-containing peptides AmpFE749-57, AmpFE744-57, $\mathrm{PFE}_{49-}$ 57, and PFE744-57, FAM-labeled peptides AmpF-FAM, PF-FAM, E749-57-FAM, and E74457-FAM. 


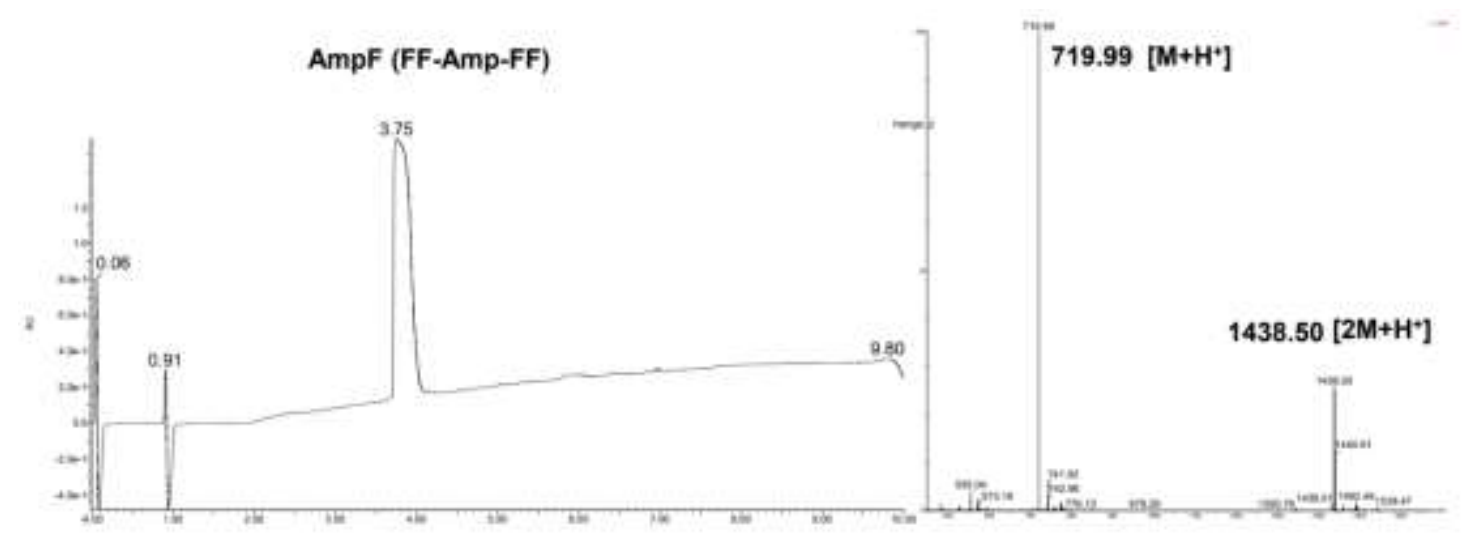

Figure S2. UPLC trace (left) and mass spectrum (right) of peptide AmpF.

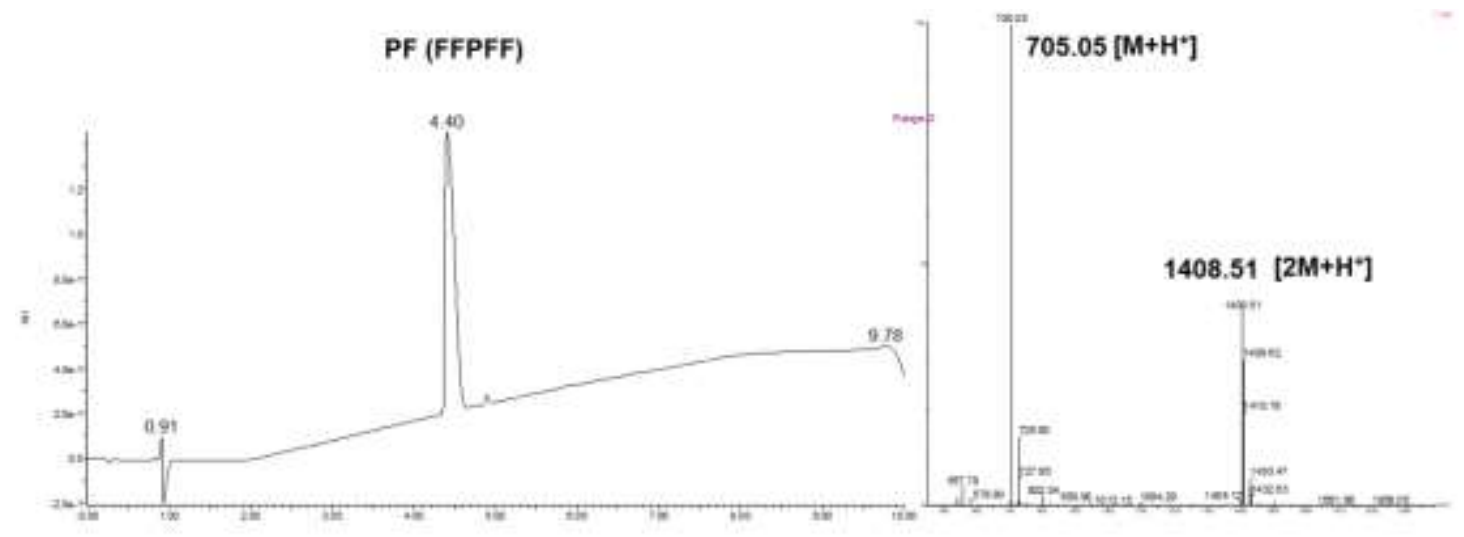

Figure S3. UPLC (left) and Mass spectrum (right) of peptide PF.

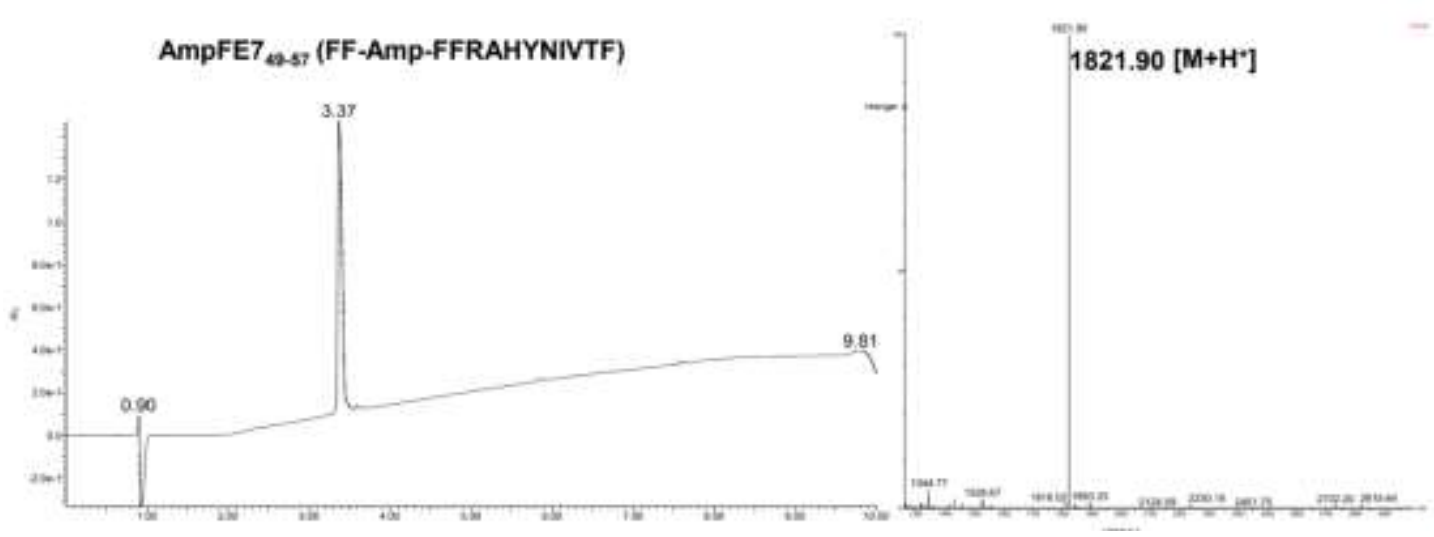

Figure S4. UPLC trace (left) and Mass spectrum (right) of peptide AmpFE749-57. 


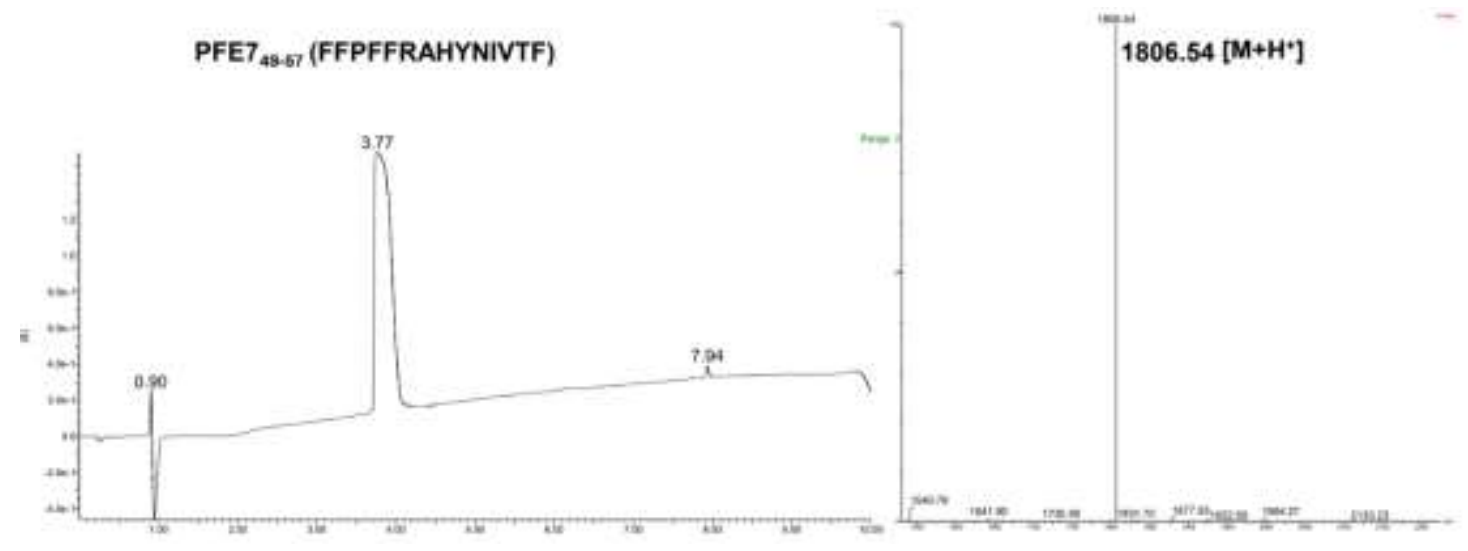

Figure S5. UPLC trace (left) and Mass spectrum (right) of peptide PFE749-57.

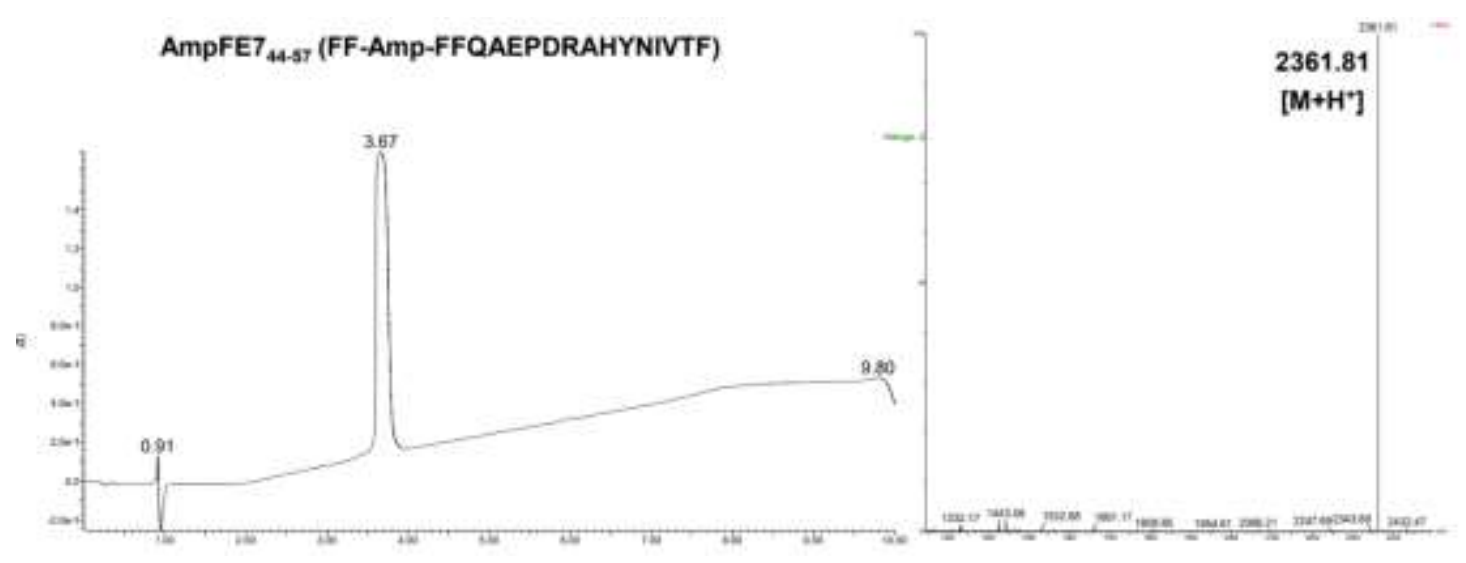

Figure S6. UPLC trace (left) and Mass spectrum (right) of peptide AmpFE744-57.

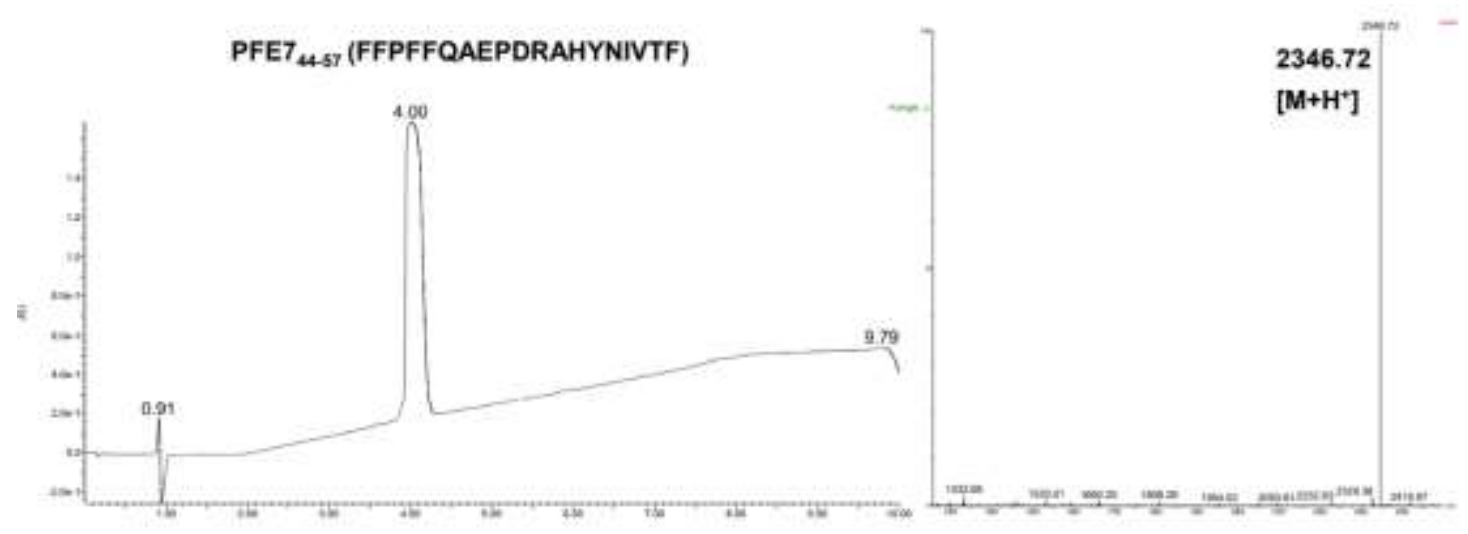

Figure S7. UPLC trace (left) and Mass spectrum (right) of peptide PFE744-57. 
E7 $_{\text {49-5) }}$ (RAHYNIVTF)

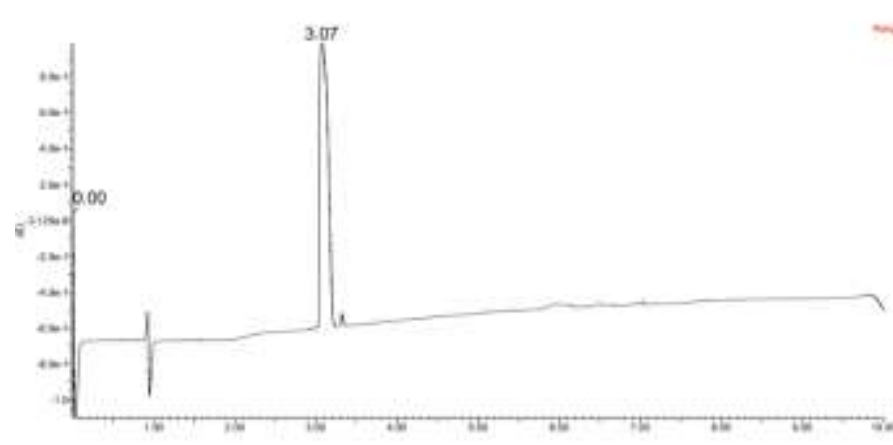

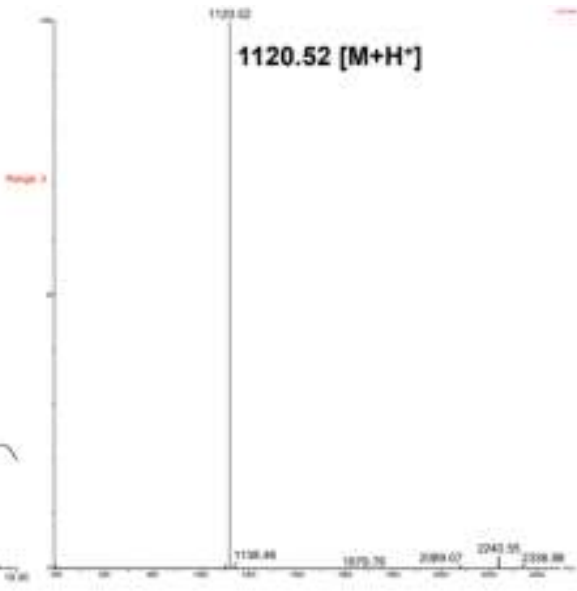

Figure S8. UPLC trace (left) and Mass spectrum (right) of peptide antigen E749-57.
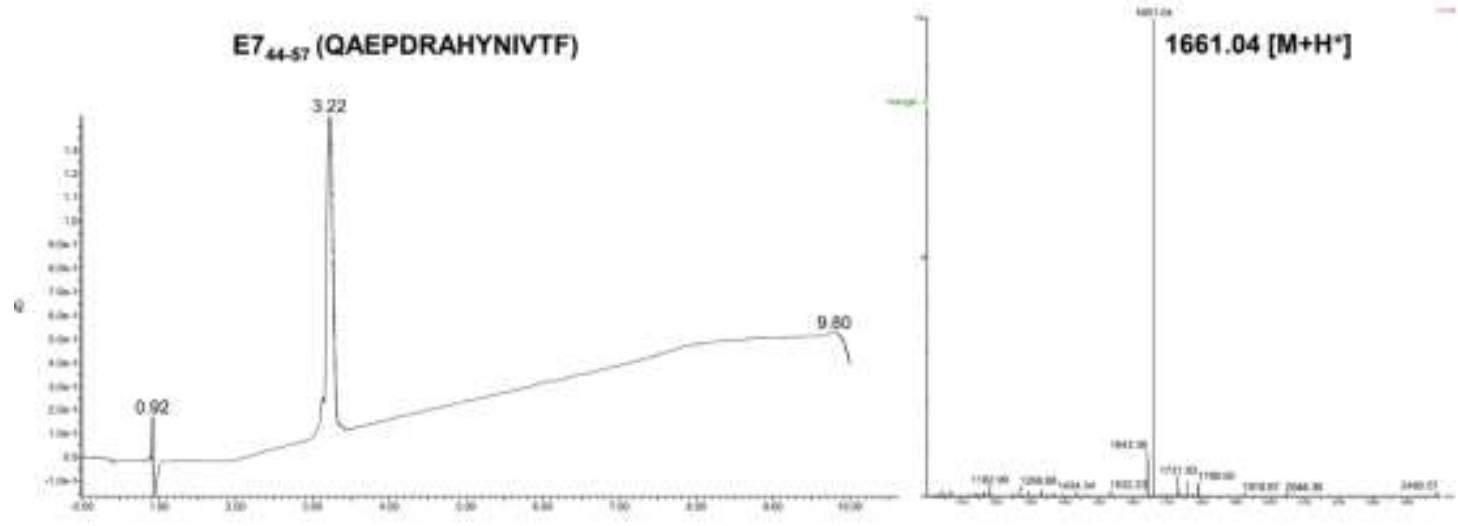

Figure S9. UPLC trace (left) and Mass spectrum (right) of peptide antigen E744-57.

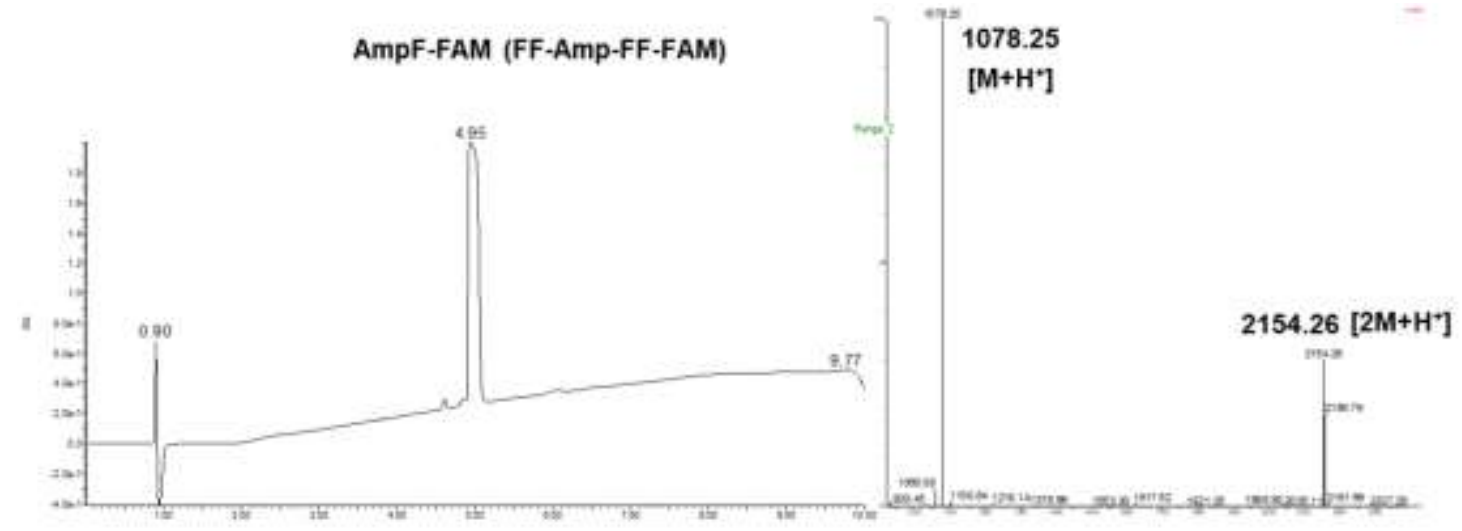

Figure S10. UPLC trace (left) and Mass spectrum (right) of peptide AmpF-FAM. 


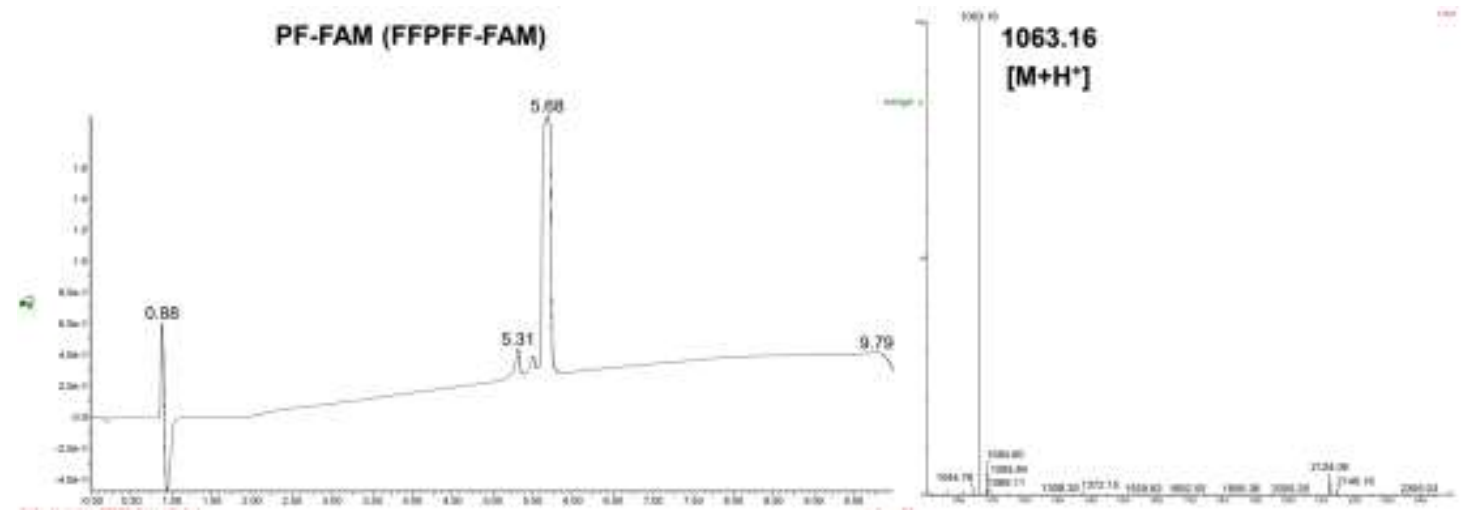

Figure S11. UPLC trace (left) and Mass spectrum (right) of peptide PF-FAM.

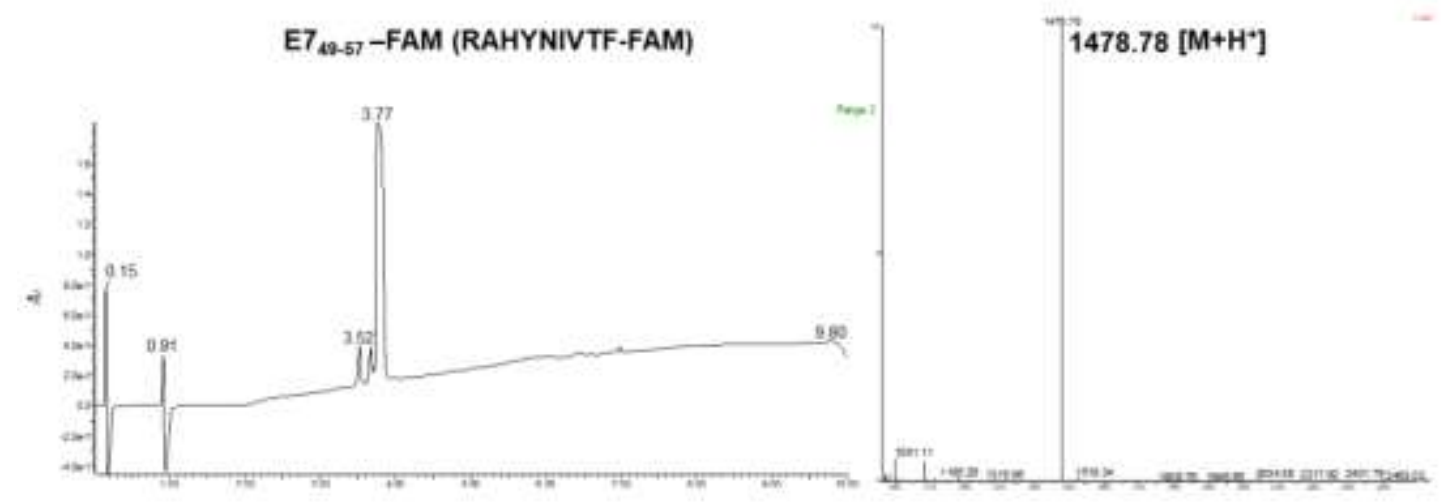

Figure S12. UPLC trace (left) and Mass spectrum (right) of peptide E749-57-FAM.

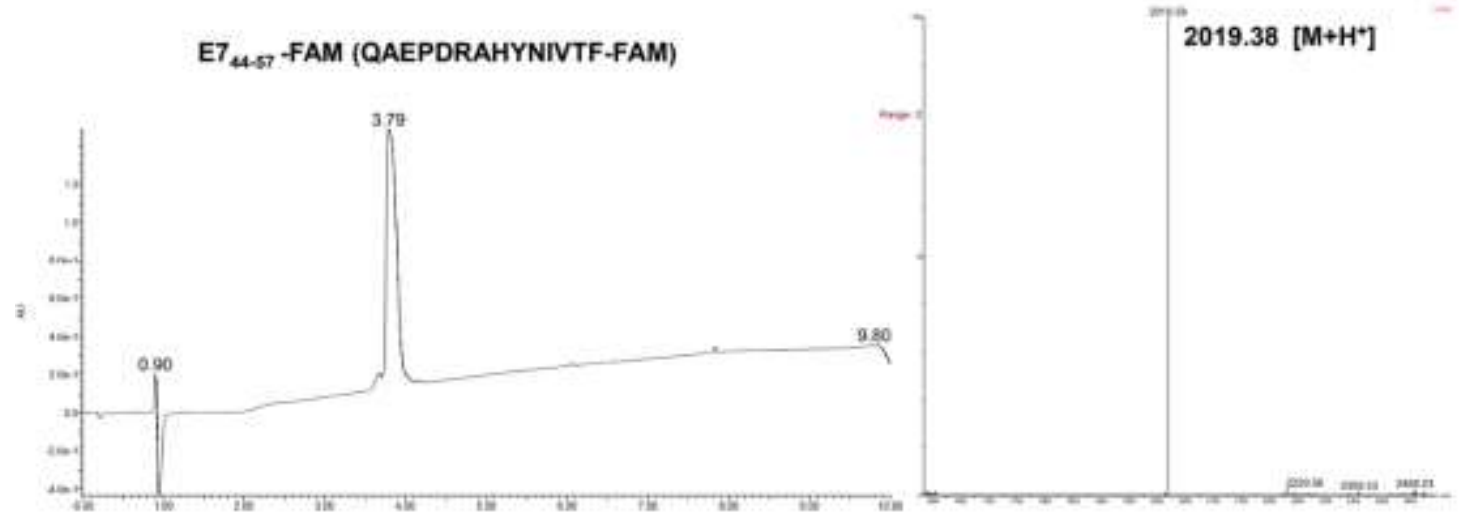

Figure S13. UPLC trace (left) and Mass spectrum (right) of peptide E744-57-FAM. 


\section{Critical aggregation concentration (CAC)}

On the basis of the shift of the maximal emission wavelength of Nile Red induced by the changes of microenvironment hydrophobicity, Nile Red was used as a fluorescent probe to measure the $\mathrm{CAC}$ values of peptide vaccines AmpF-E749-57, AmpF-E744-57, PFE749-57, and PF-E744-57. The fluorescence spectra of Nile Red were recorded by fluorescence spectrophotometer (Agilent Cary Eclipse) in the range from 600 to $700 \mathrm{~nm}$ with an excitation wavelength of $550 \mathrm{~nm}$. The slit widths for the excitation and emission light sources were set as $10 \mathrm{~nm}$. The Nile Red ethanol solution $(2 \mu \mathrm{L} 100 \mu \mathrm{M})$ was added to each peptide $(2 \mathrm{~mL})$ with different concentrations and incubated overnight for measurement. The wavelength of maximum fluorescence emission of Nile Red was plotted as a function of peptide concentrations to estimate the CAC value. 

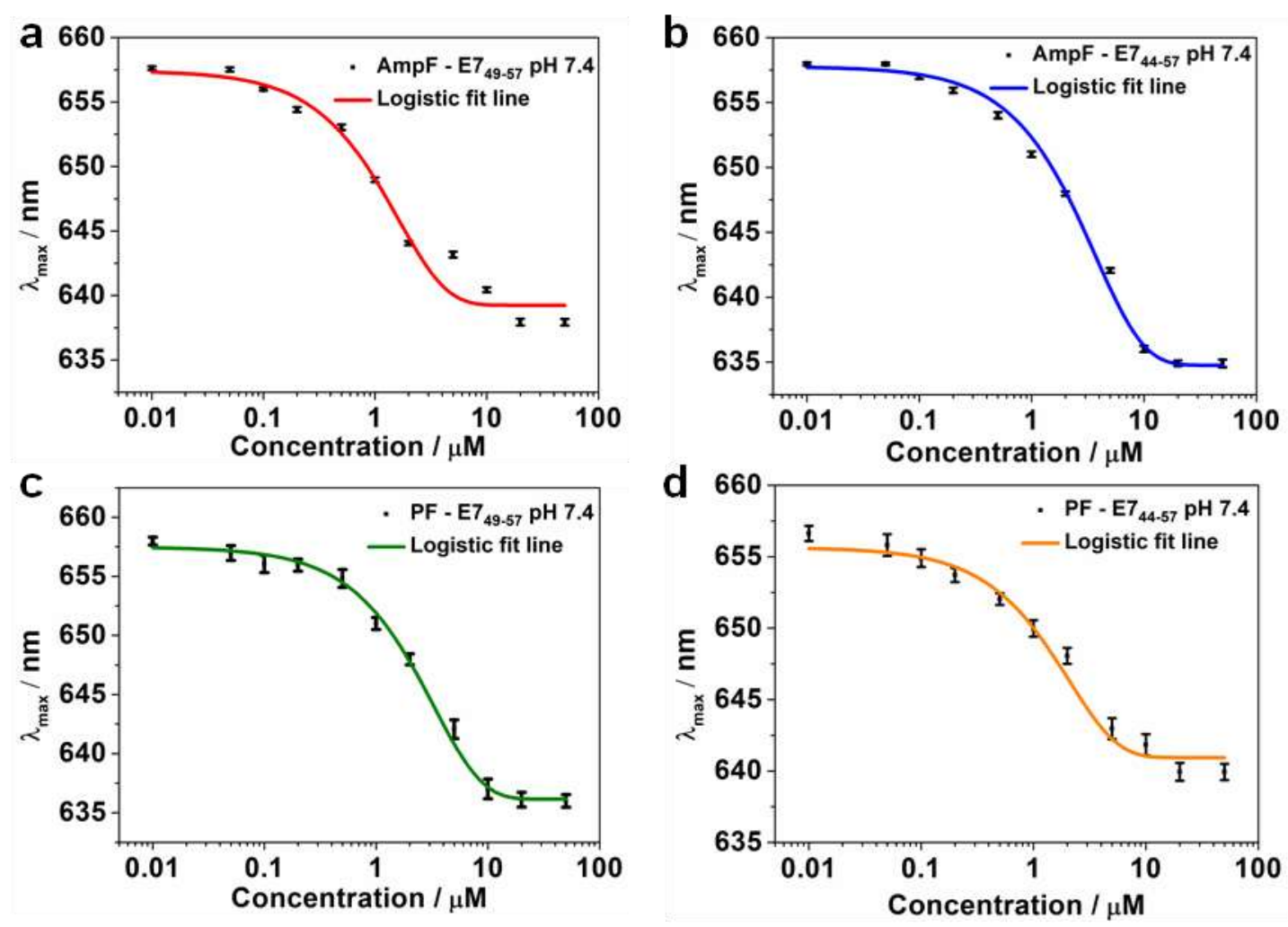

Figure S14. The wavelength of the maximal fluorescence emission ( $\lambda \max )$ of Nile Red in the presence of peptide vaccines AmpF-E749-57 (a), AmpF-E744-57 (b), PF-E749-57 (c), and PF-E744-57 (d) as a function of peptide concentrations in the range of 0.01 and $50 \mu \mathrm{M}$.

\section{Circular dichroism (CD) spectroscopy.}

CD spectra of pentapeptides AmpF, PF, peptide vaccines AmpF-E749-57, AmpF-E744-57, PF-E749-57, and PF-E744-57, peptide antigens E749-57 and E744-57 were recorded by a spectrometer (Biologic MOS-500). The aged peptide solutions with a concentration of $2 \mathrm{mM}$ was transfered in the $0.1 \mathrm{~mm}$ quartz slides for scanning. The sepctra were recorded with an interval of $1.0 \mathrm{~nm}$ in the range from $190 \mathrm{~nm}$ to $250 \mathrm{~nm}$. 


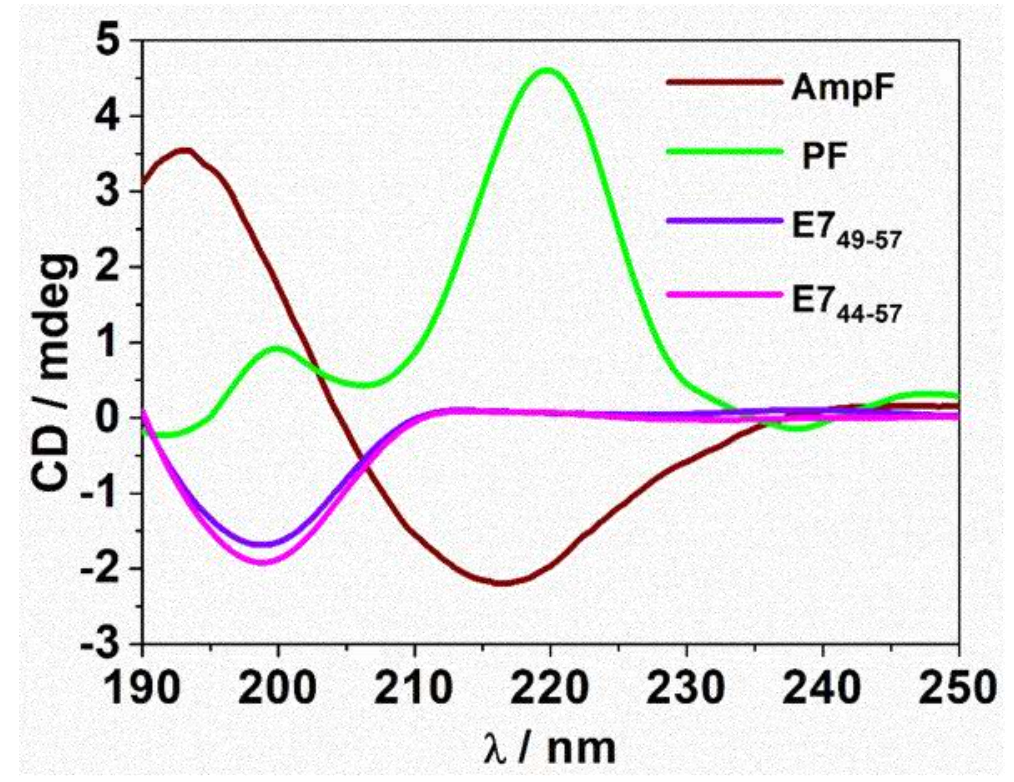

Figure S15. CD spectra of pentapeptides AmpF and PF, antigen peptides E749-57 and $\mathrm{E}_{44-57}$ at $\mathrm{pH} 7.4$.

\section{Thioflavin T (ThT) binding assay}

The fluorescence spectrophotometer (Agilent Cary Eclipse) was used to record fluorescence spectra of ThT in the presence or absence of peptides. The solution of ThT $(20 \mu \mathrm{M})$ was incubated in the presence of peptide vaccines AmpF-E749-57, AmpF-E74457, PF-E749-57, and PF-E744-57 (2 mM) overnight and then used for measurements. During the measurements, a quartz cell with an optical path of $1 \mathrm{~cm}$ was used. The fluorescence spectra were recorded with an excitation wavelength of $421 \mathrm{~nm}$ in the range from 450 to $600 \mathrm{~nm}$. The slit widths for the excitation and emission light sources were set as $20 \mathrm{~nm}$. 

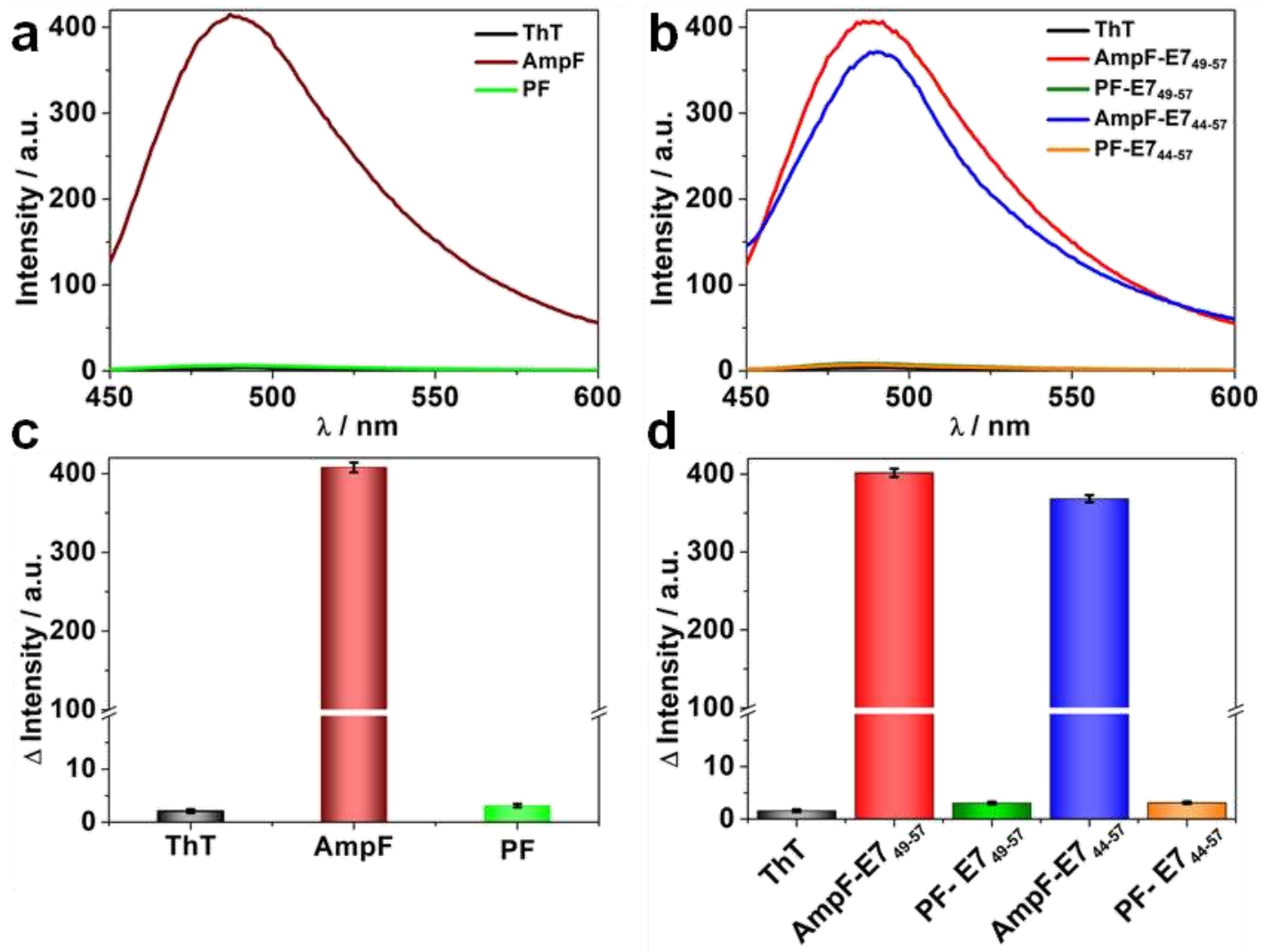

Figure S16. ( $a$ and b) Fluorescence spectra of ThT solutions in the absence or presence of peptides AmpF and PF (a), or peptide vaccines AmpF-E749-57, AmpF-E744-57, PFE749-57, and PF-E744-57 (b) at pH 7.4. (c and d) The fluorescence intensity at the maximal emission (@483 nm) of ThT molecules in the presence of peptides AmpF and PF (c), or peptide vaccines AmpF-E749-57, AmpF-E744-57, PF-E749-57, and PF-E744-57 (d).

\section{Atom force microscopy (AFM).}

Under the tapping mode, the Bruker ICON instrument was used to record the AFM images of the peptide vaccines. Firstly, the aged solution of peptide vaccines AmpFE749-57, AmpF-E744-57, PF-E749-57, and PF-E744-57 $(10 \mu \mathrm{L})$ with a concentration of $2 \mathrm{mM}$ was dropped on the surface of the mica sheet and allowed to stand for 5 minutes. Blotting the remained solution and drying under atmosphere condition led to the AFM 
samples for testing.

\section{Transmission electron microscopy (TEM).}

The TEM image was acquired on a Philips Tecnai G2 20 S-TWIN microscope. The aged solutions of peptide vaccines AmpF-E749-57, AmpF-E744-57, PF-E749-57, and PF$\mathrm{E}_{44-57}(2 \mathrm{mM}, 10 \mu \mathrm{L})$ were added to the surface of the carbon-coated copper grid and stand for 5 minutes. After blotting the solutions by filter paper, $10 \mu \mathrm{L}$ of $2 \mathrm{wt} \%$ uranyl acetate was subsequently added to the grid surface, which was removed by filter paper after $3 \mathrm{~min}$. The samples were stored in a desiccator before testing.

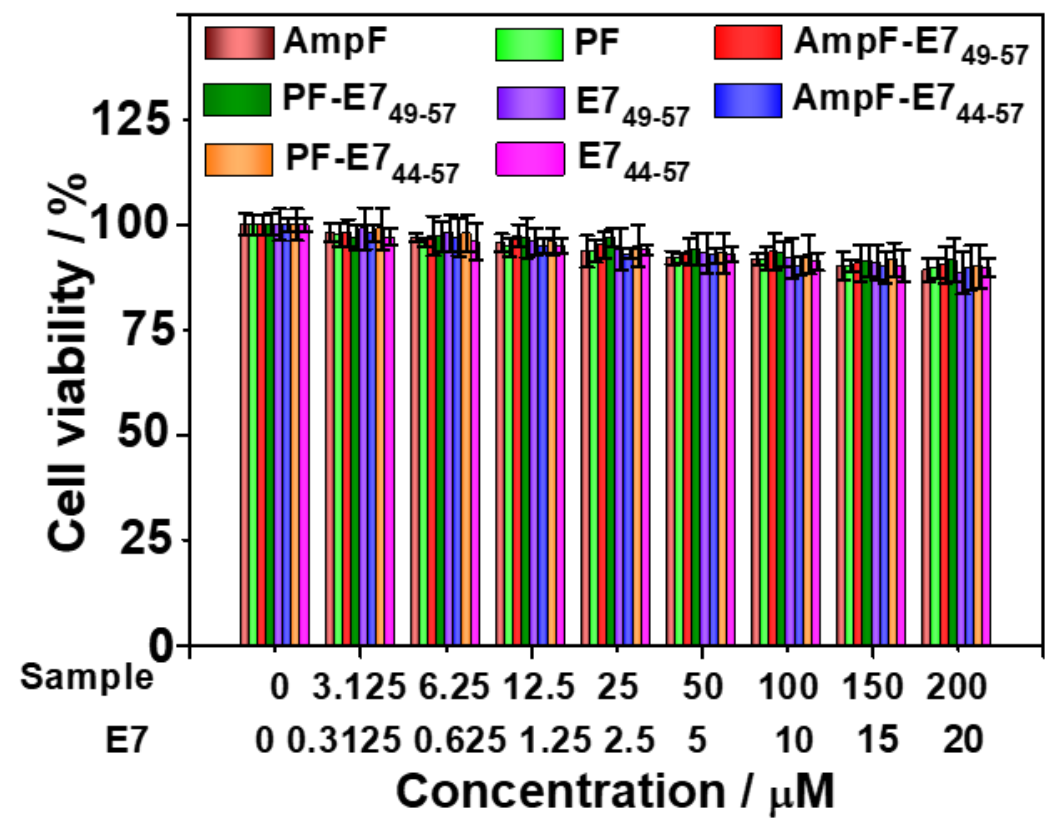

Figure S17. Cell viability of $3 \mathrm{~T} 3$ cells cultured in the presence of pentapeptides AmpF and PF, peptides vaccines AmpF-E749-57, PF-E749-57, AmpF-E744-57, and PF-E744-57, peptides antigens $\mathrm{E} 7_{49-57}$ and $\mathrm{E} 7_{44-57 .}$ 


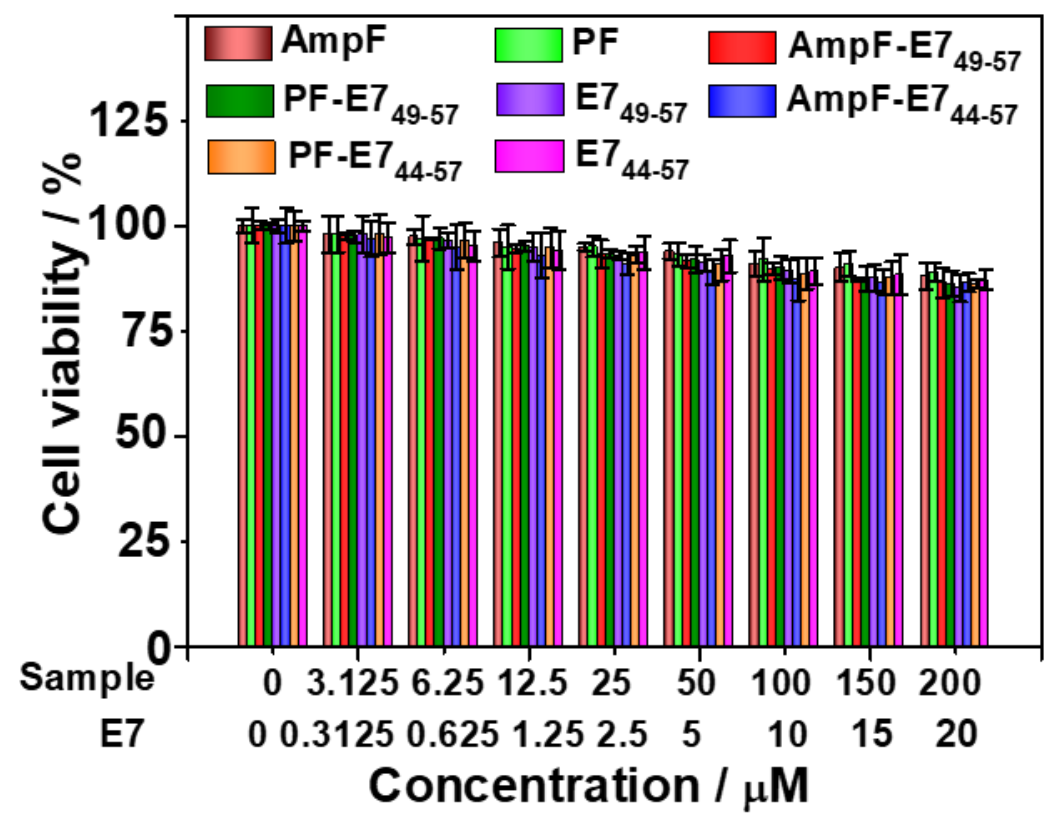

Figure S18. Cell viability of DC 2.4 cells cultured in the presence of pentapeptides AmpF and PF, peptides vaccines AmpF-E749-57, PF-E749-57, AmpF-E744-57, and PF-E74457, peptides antigens E749-57 and E744-57.

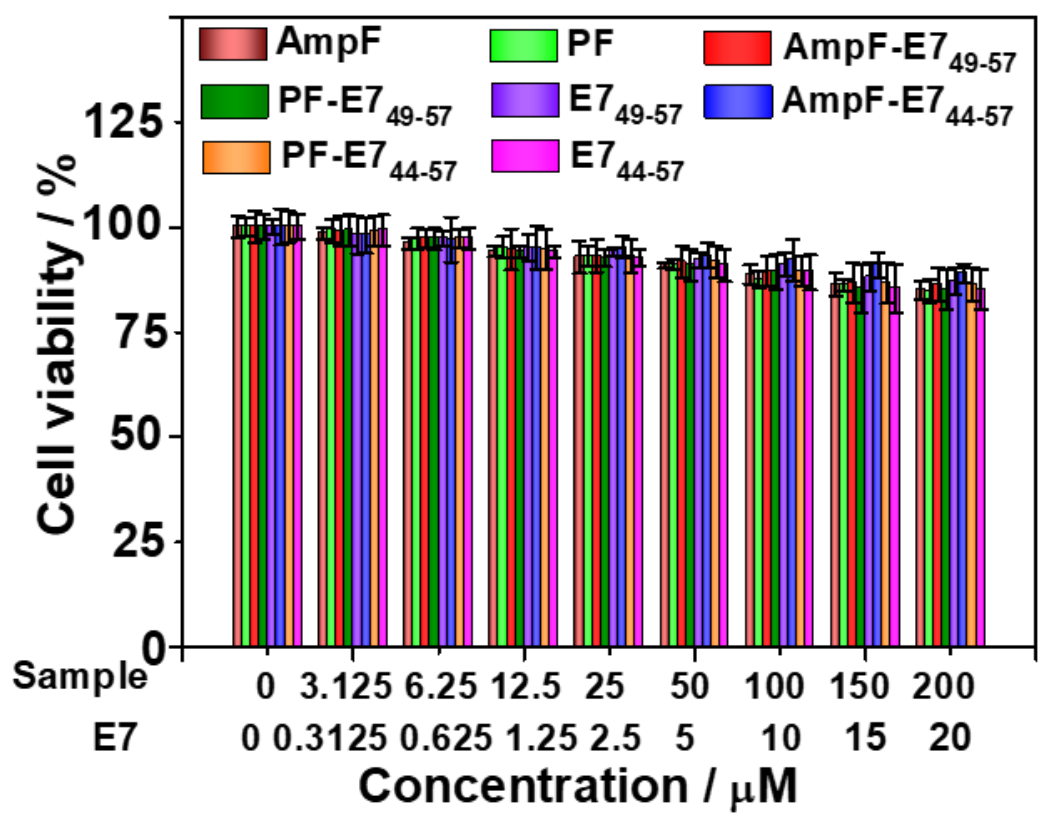

Figure S19. Cell viability of TC-1 cells cultured in the presence of pentapeptides AmpF and PF, peptides vaccines AmpF-E749-57, PF-E749-57, AmpF-E744-57, and PF-E744-57, 
peptides antigens $\mathrm{E}_{49-57}$ and $\mathrm{E} 7_{44-57 .}$

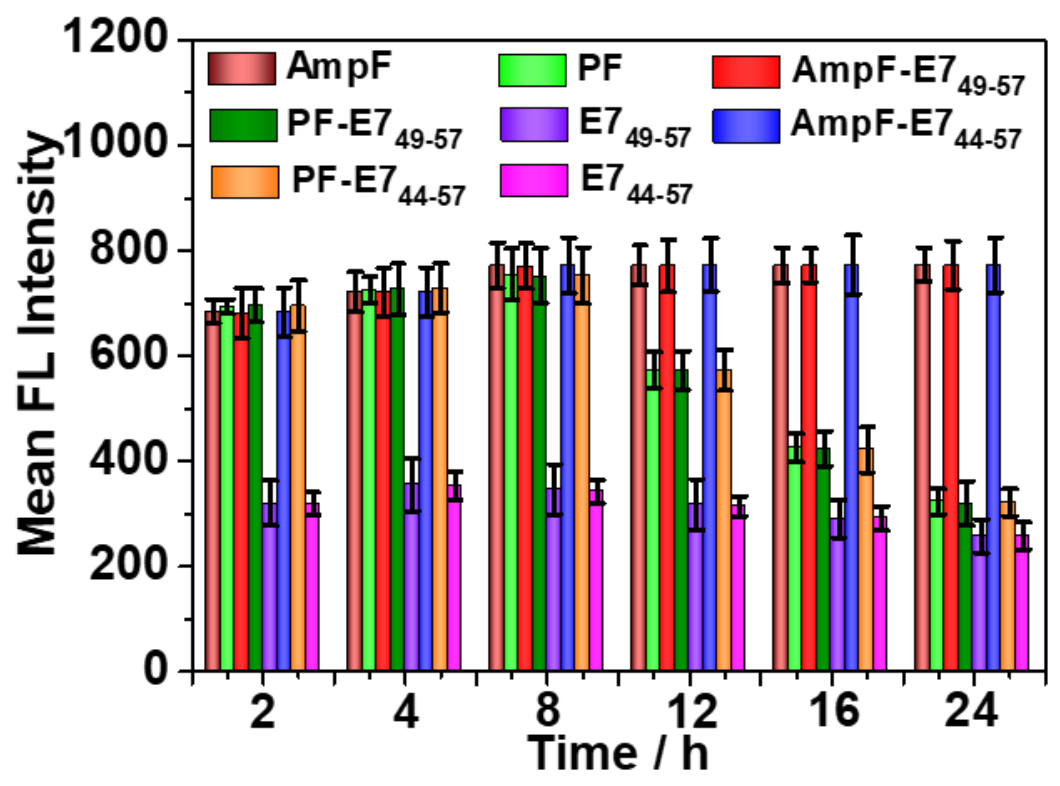

Figure S20. Quantificative fluorescence intensity of DC2.4 cells cultured in the presence of pentapeptides AmpF and PF, peptides vaccines AmpF-E749-57, PF-E749-57, AmpF-E744-57, and PF-E744-57, peptides antigens E749-57 and E744-57 containing FAMlabeled peptides.

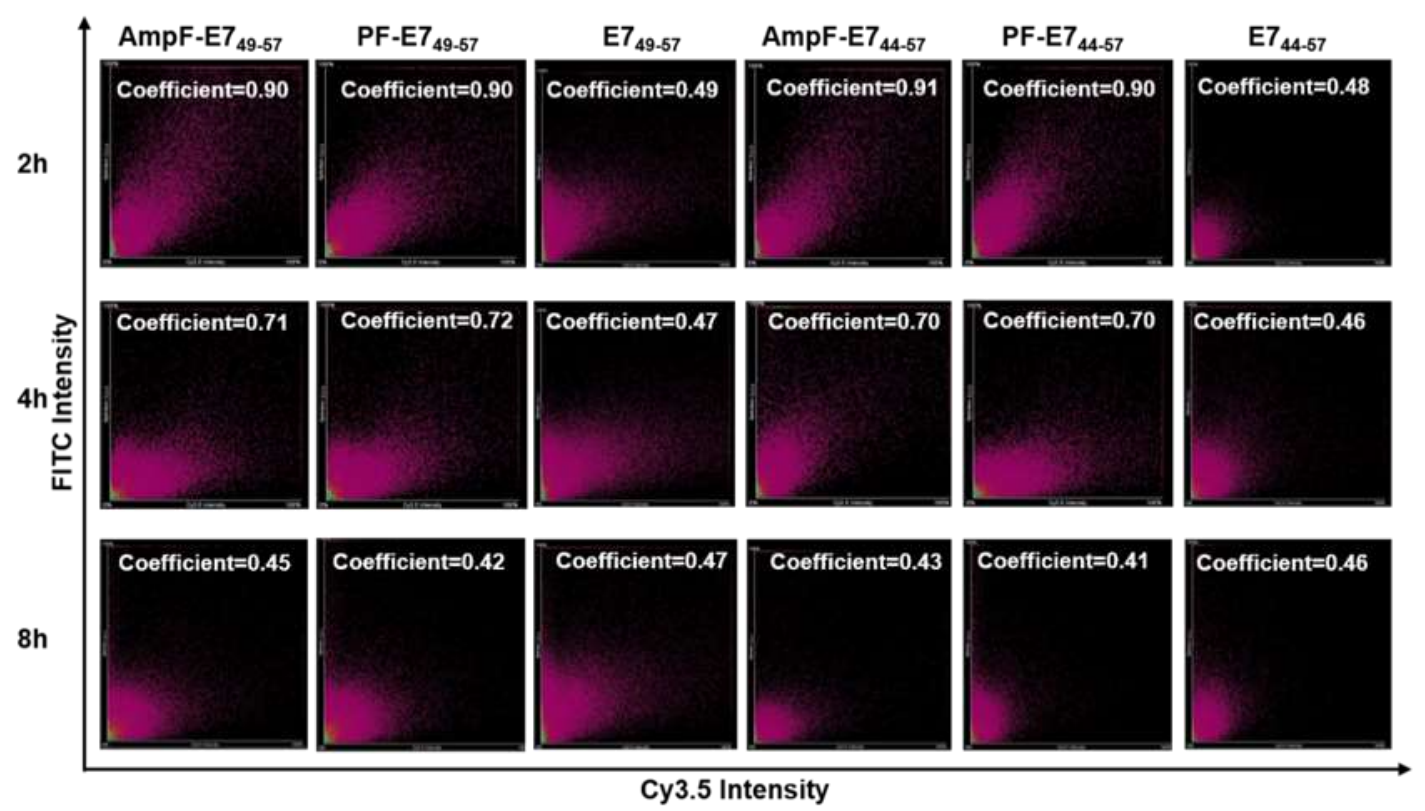

Figure S21. The Pearson's correlation coefficient between LysoTracker and FAM 
signals of DC2.4 Cells treated with peptides vaccines AmpF-E749-57, PF-E749-57, AmpFE744-57, PF-E744-57, and peptides antigens E749-57 and E744-57 for $2 \mathrm{~h}, 4 \mathrm{~h}$ and $8 \mathrm{~h}$.
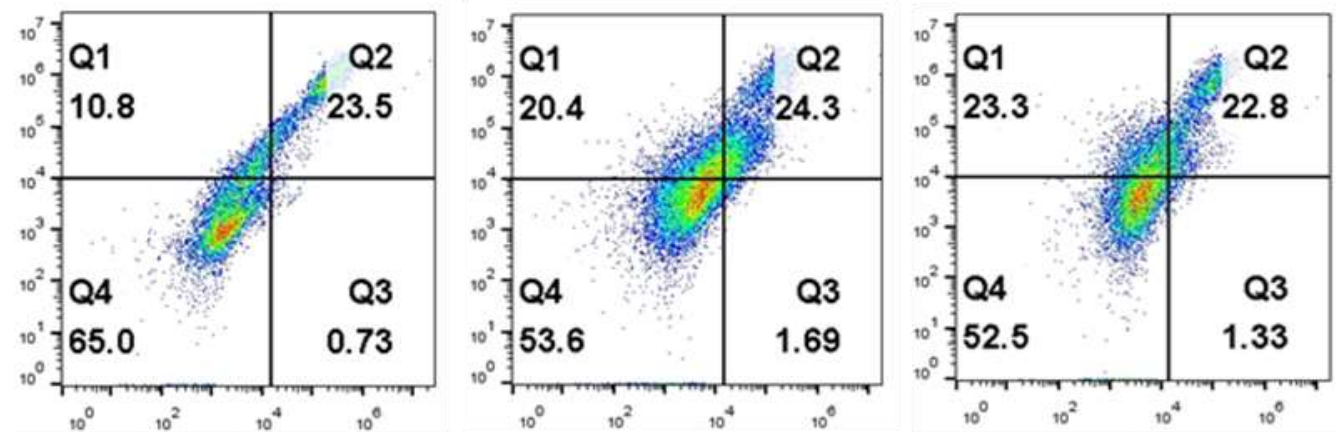

Control

$\mathrm{AmpF}$

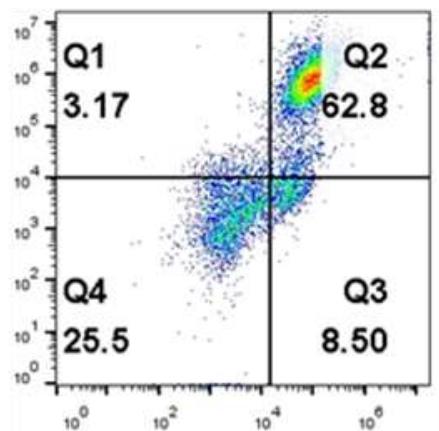

AmpF-E7 ${ }_{49-57}$

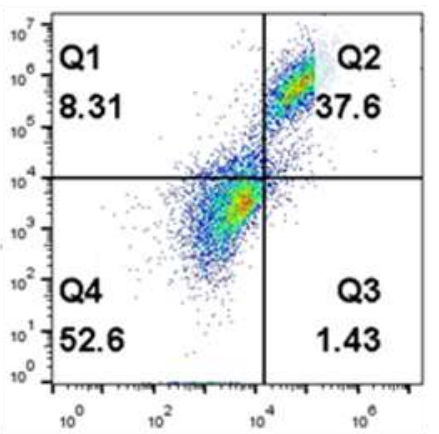

$\mathrm{PF}$
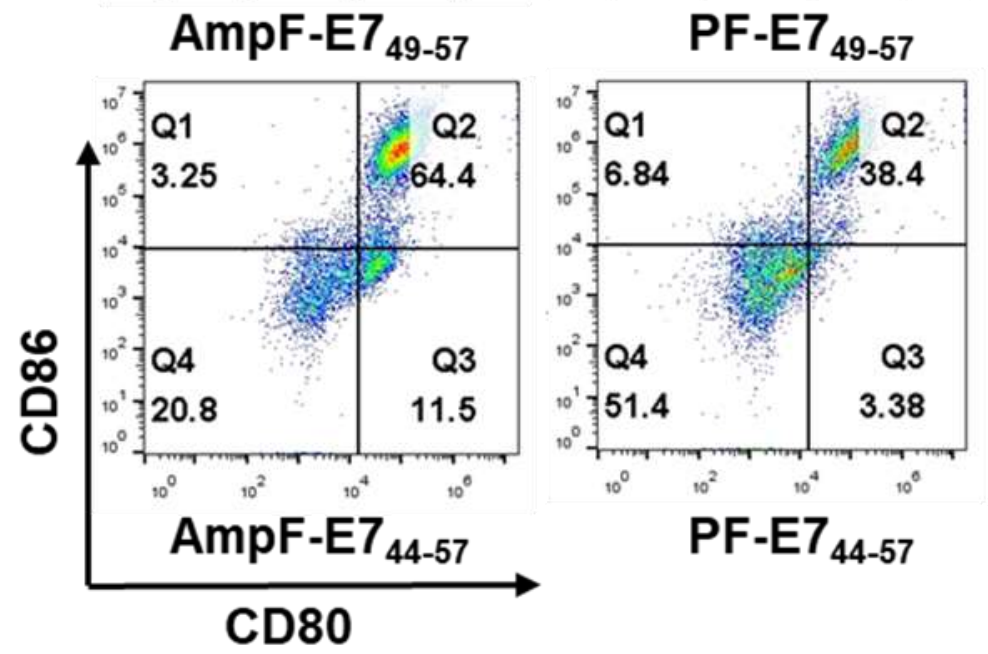

PF-E7 $44-57$
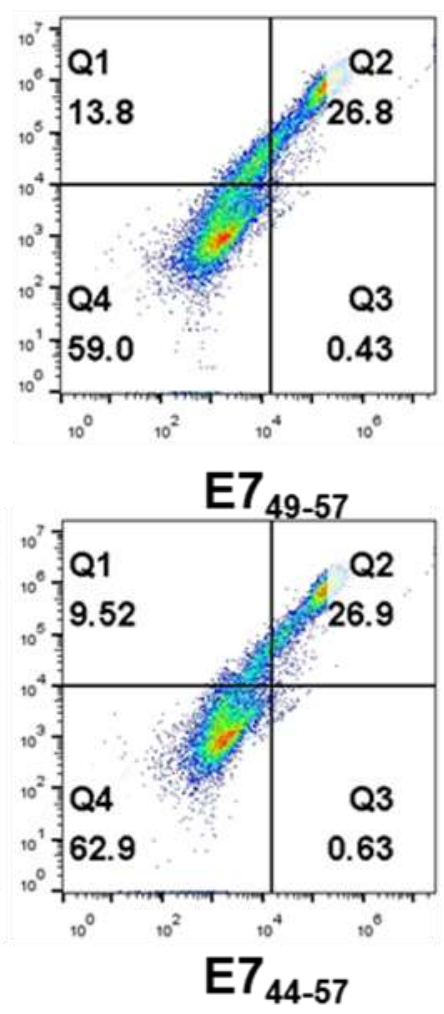

Figure S22. Representative FACS plots of stimulator molecules CD86 and CD80 on BMDCs treated with PBS, pentapeptides AmpF and PF, peptides vaccines AmpF-E749-

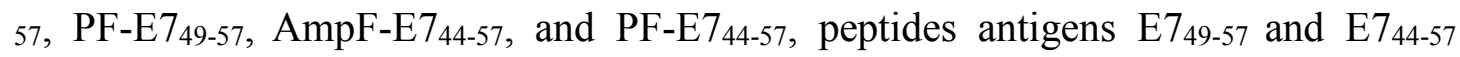
detected by flow cytometer. 
a

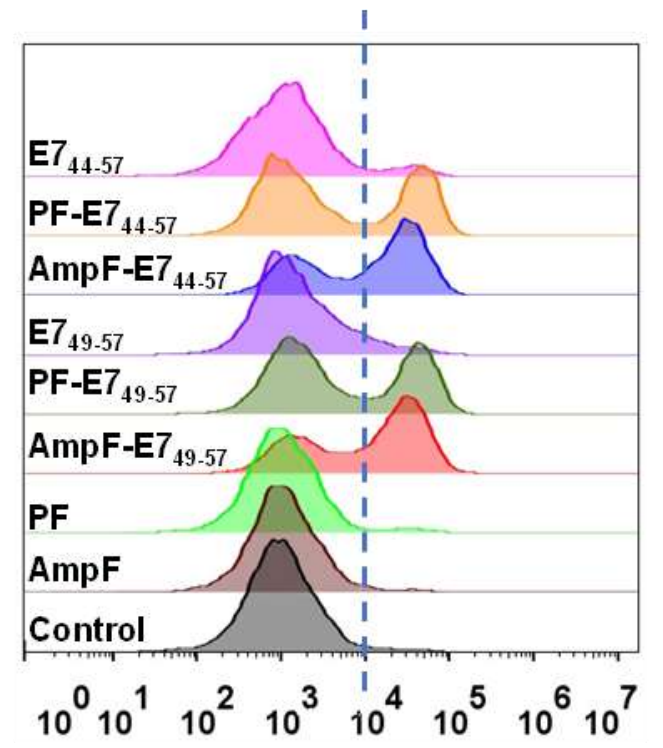

b

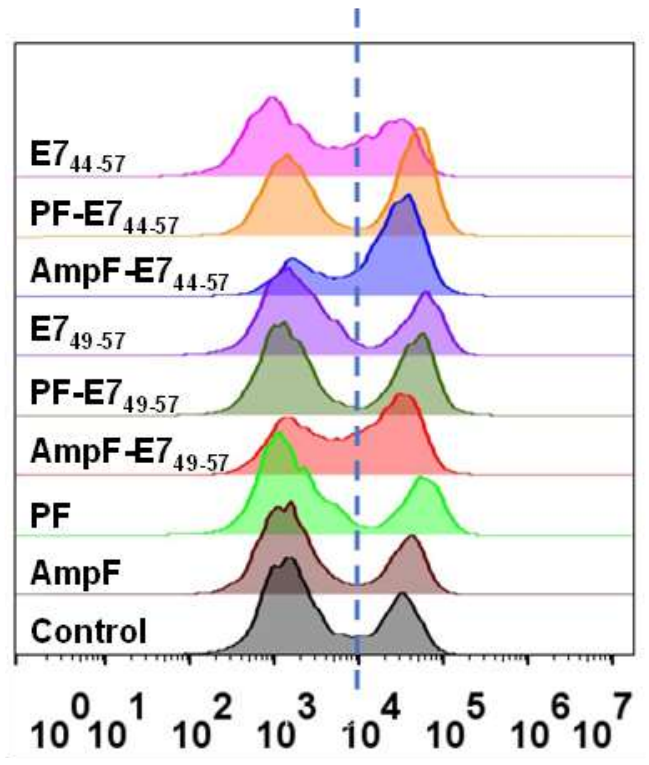

Figure S23. Expressions of MHC-I (a) and MHC-II (b) of BMDCs treated with PBS, pentapeptides AmpF and PF, peptides vaccines AmpF-E749-57, PF-E749-57, AmpF-E74457, and PF-E744-57, peptides antigens E749-57 and E744-57 containing FAM-labeled peptides evaluated by flow cytometer. 

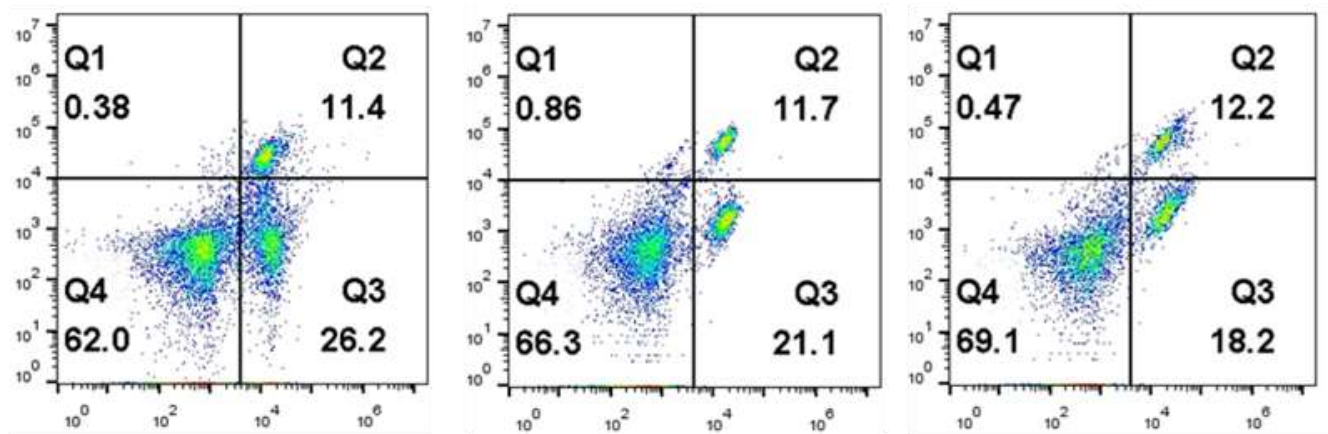

\section{Control}
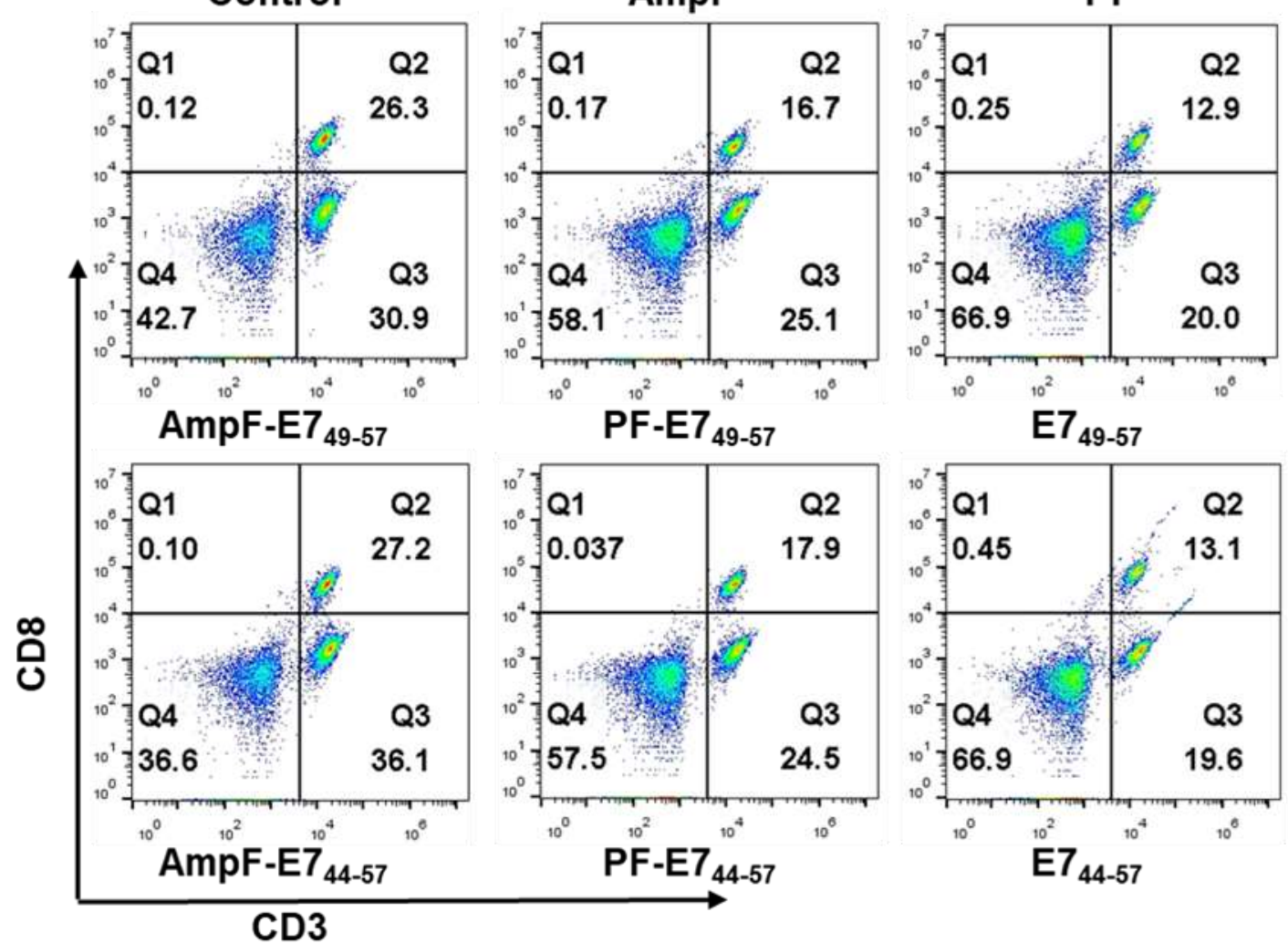

$E 7_{49-57}$

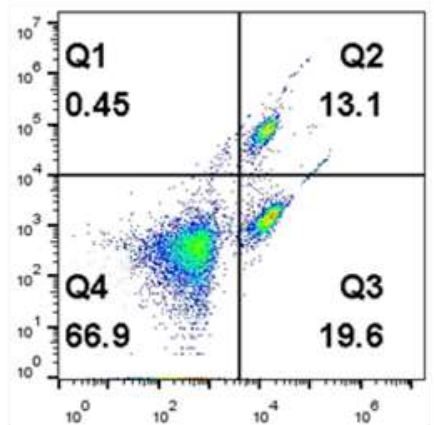

$E 7_{44-57}$

Figure S24. Representative FACS plots of splenocyte $\mathrm{CD} 3^{+} \mathrm{CD} 8^{+} \mathrm{T}$ cells after incubating with BMDCs pretreated by PBS, pentapeptides AmpF and PF, peptides vaccines AmpF-E749-57, PF-E749-57, AmpF-E744-57, and PF-E744-57, peptides antigens E749-57 and E744-57 containing FAM-labeled peptides estimated by flow cytometer. 

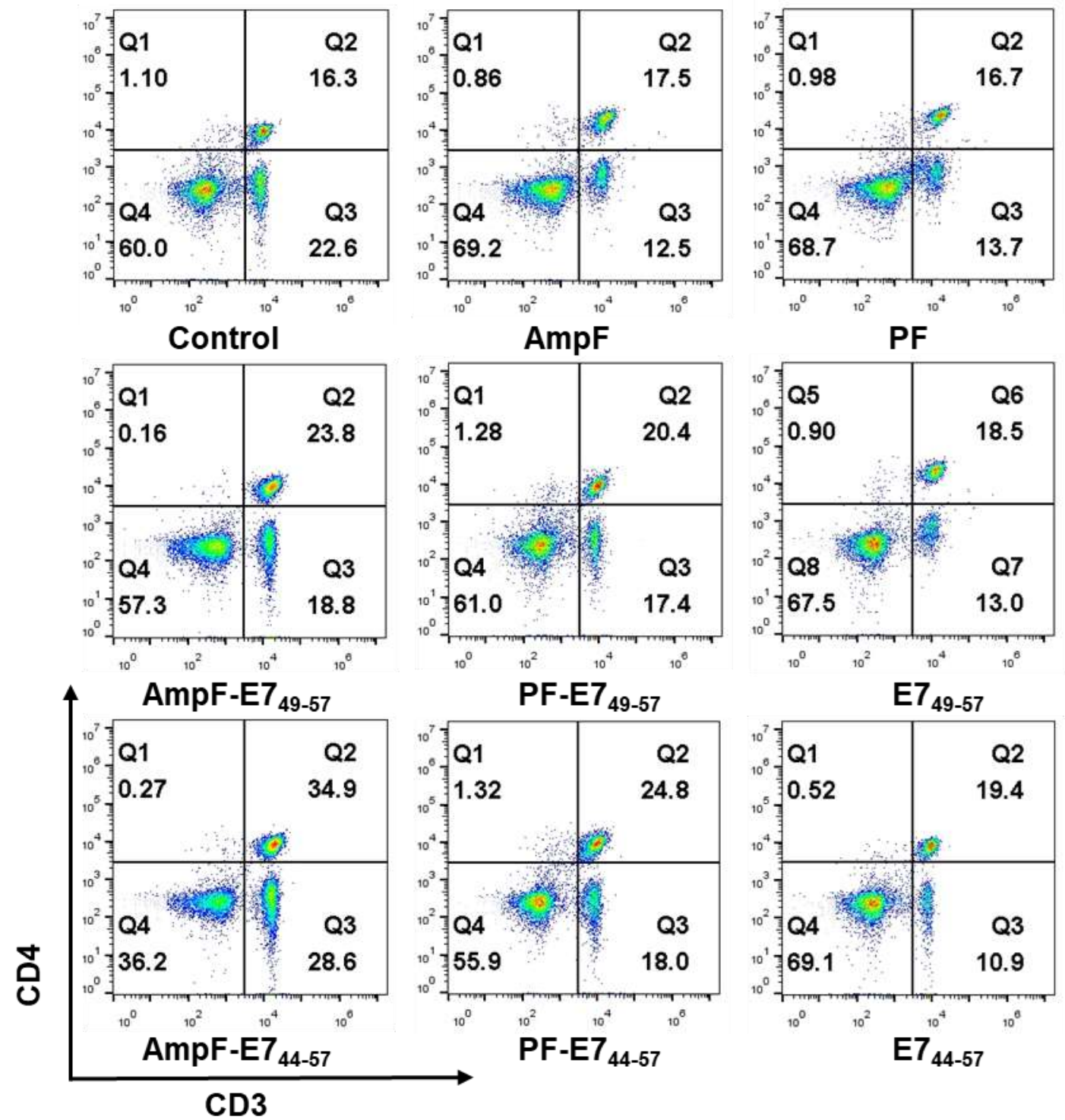

Figure S25. Representative FACS plots of splenocyte $\mathrm{CD} 3^{+} \mathrm{CD} 4^{+} \mathrm{T}$ cells after incubating with BMDCs pretreated by PBS, pentapeptides AmpF and PF, peptides vaccines AmpF-E749-57, PF-E749-57, AmpF-E744-57, and PF-E744-57, peptides antigens E749-57 and E744-57 containing FAM-labeled peptides estimated by flow cytometer. 


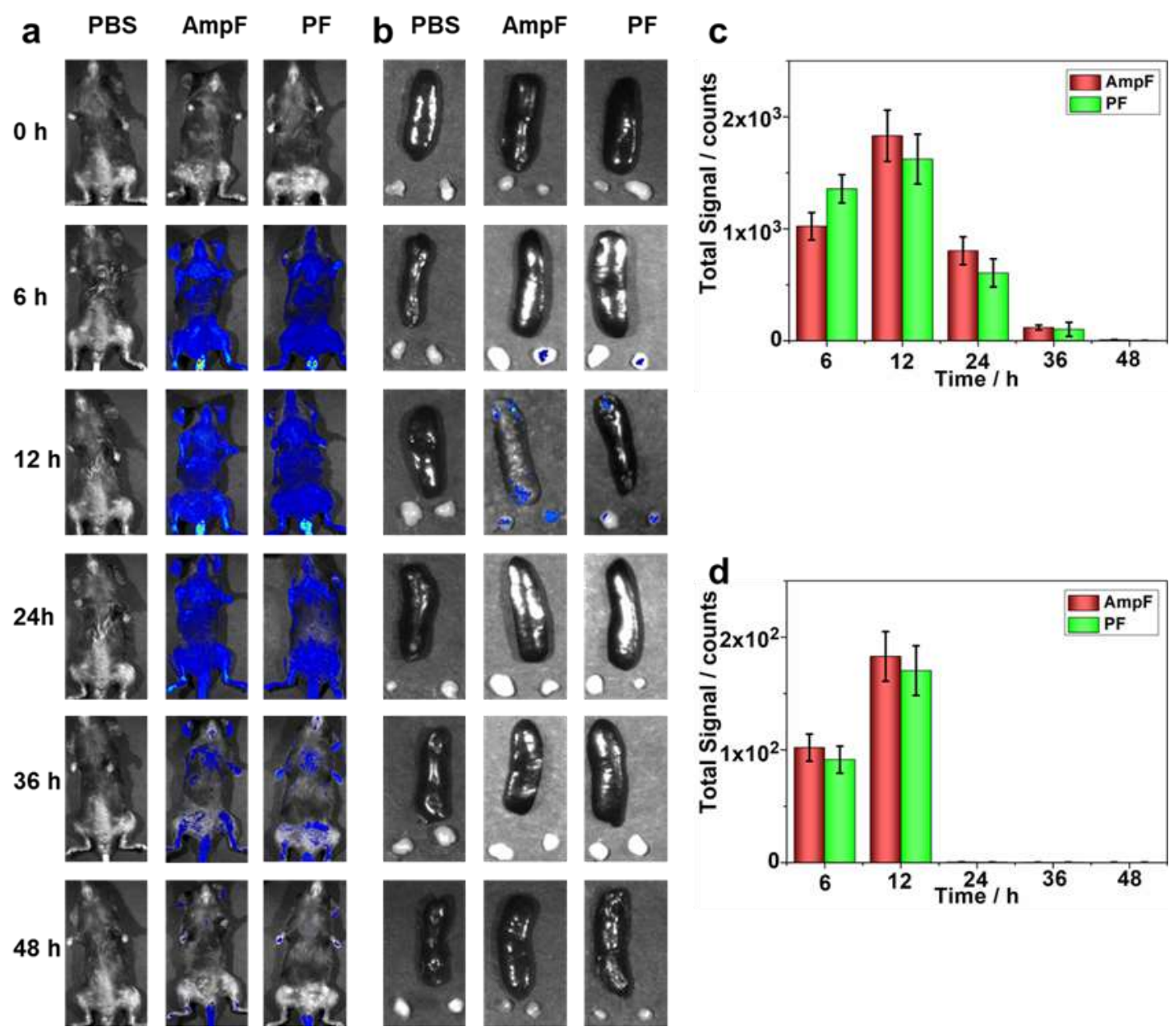

Figure S26. (a) In vivo fluorescence imaging of the mice after the subcutaneous injection of PBS, FAM-labeled peptides AmpF and PF at the tail base of each mice at the indicated time points. (b) Ex-vivo fluorescent images of spleens (top) and LNs (bottom) dissected from the mice at the indicated time points after subcutaneous injection of FAM-labeled peptides AmpF and PF. (c and d) Quantificative fluorescence intensity of the in vivo (d) and ex vivo (d) LNs and spleen from the mice administrated with pentapeptides $\mathrm{AmpF}$ and PF. 

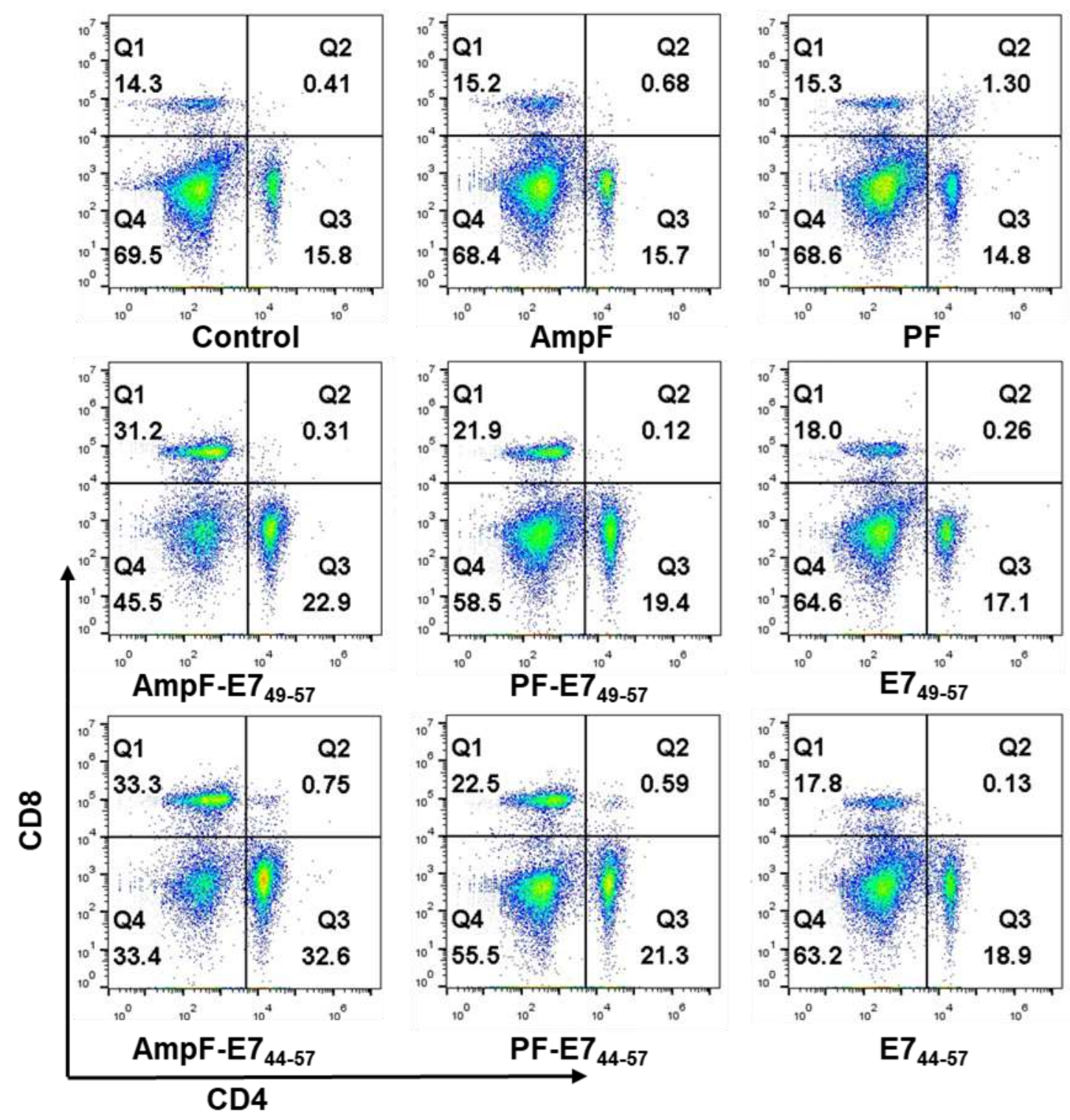

Figure S27. Representative FACS plots of $\mathrm{CD} 4^{+} \mathrm{CD} 8^{+} \mathrm{T}$ cells in the LNs dissected from mice at 48 hour post-administration of PBS, pentapeptides AmpF and PF, peptides vaccines AmpF-E749-57, PF-E749-57, AmpF-E744-57, and PF-E744-57, peptides antigens E749-57 and E744-57 analyzed by flow cytometer. 

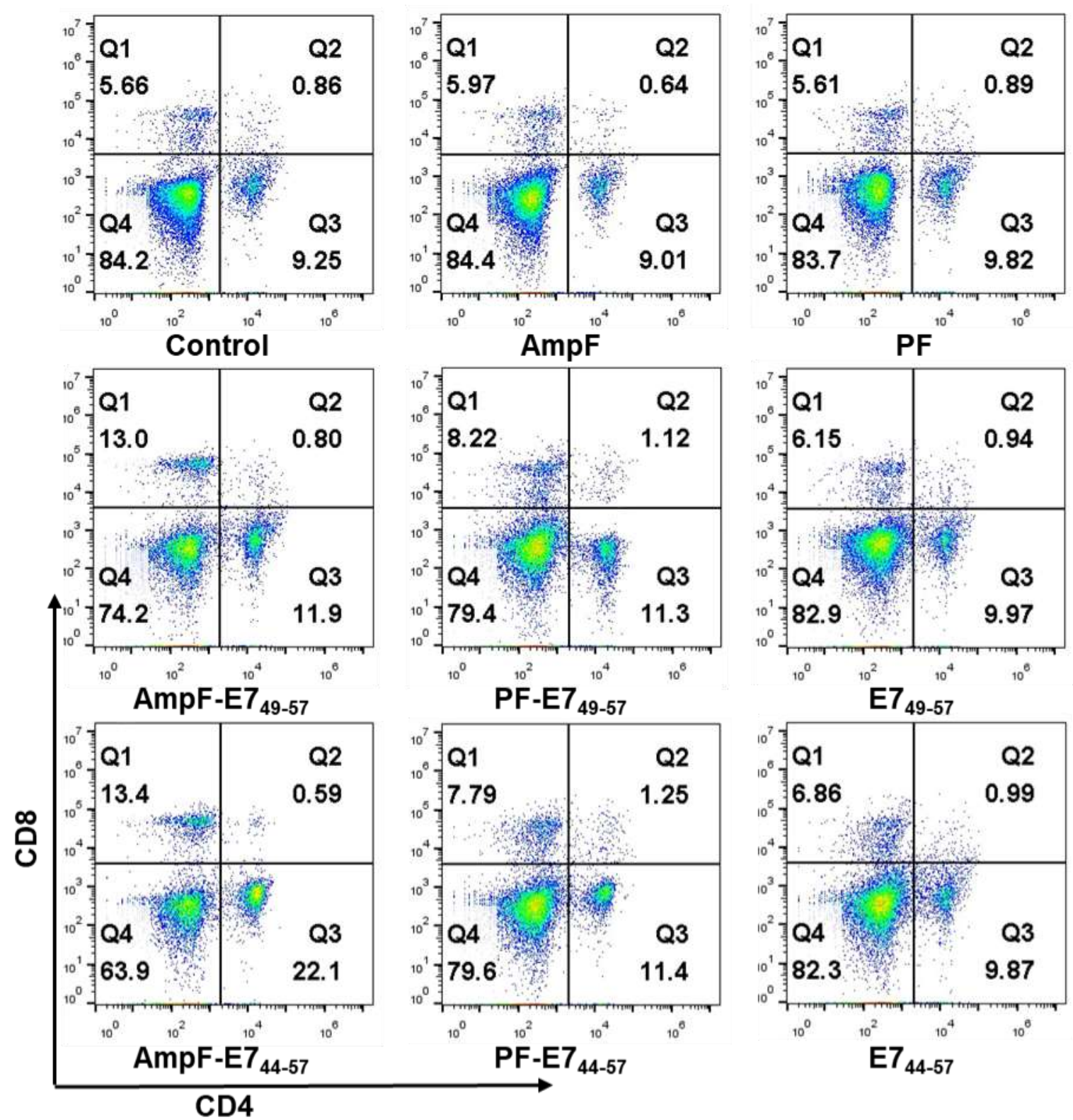

Figure S28. Representative FACS plots of $\mathrm{CD} 4^{+} \mathrm{CD} 8^{+} \mathrm{T}$ cells in the spleens dissected from mice at day 21 post-administration of PBS, pentapeptides AmpF and PF, peptides vaccines AmpF-E749-57, PF-E749-57, AmpF-E744-57, and PF-E744-57, peptides antigens E749-57 and E744-57 analyzed by flow cytometer. 

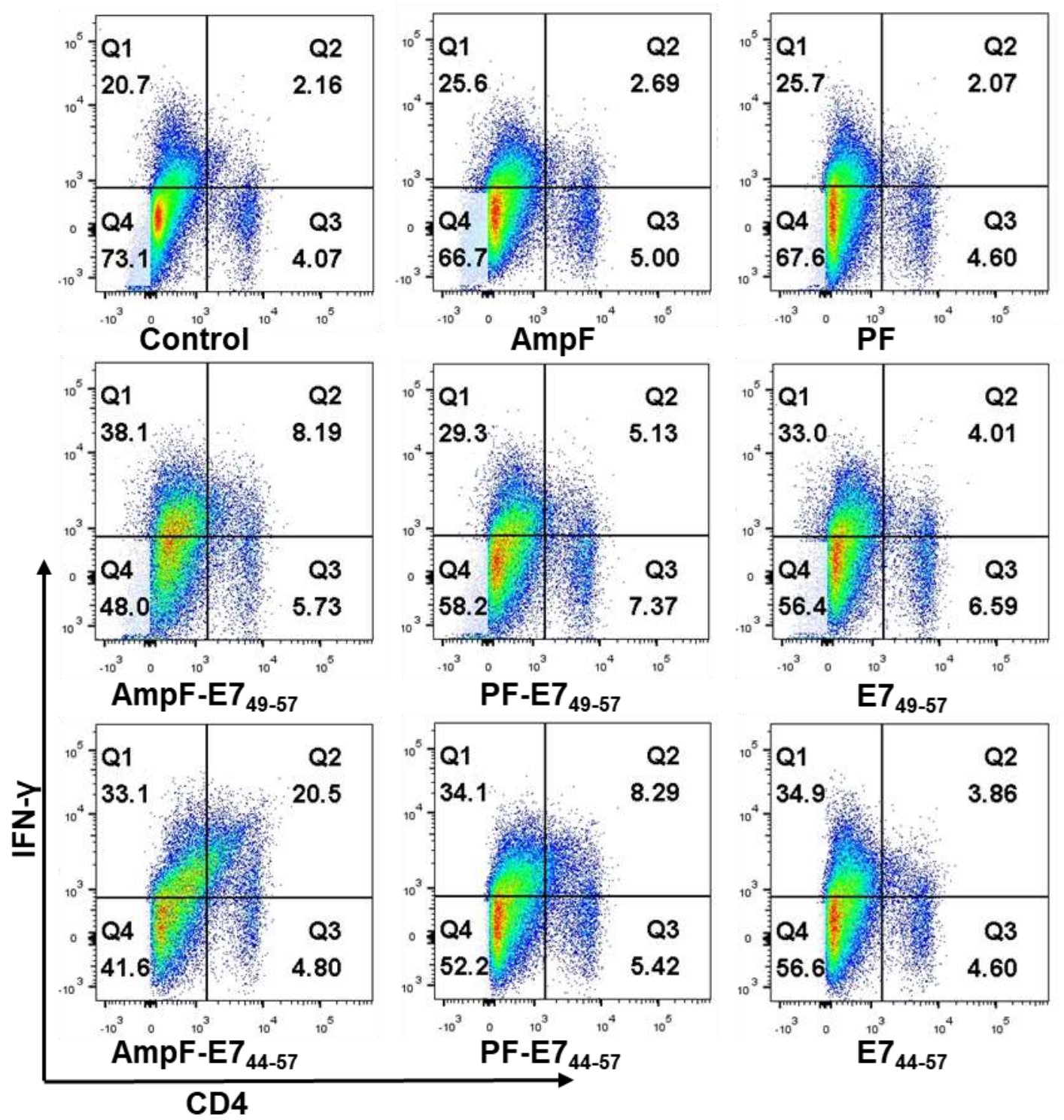

$E 7_{44-57}$

Figure S29. Representative FACS plots of CD4 $4^{+} \mathrm{IFN}-\gamma^{+}$T cells in the spleens dissected from mice at day 21 post-administration of PBS, pentapeptides AmpF and PF, peptides vaccines AmpF-E749-57, PF-E749-57, AmpF-E744-57, and PF-E744-57, peptides antigens E749-57 and E744-57 after the immunotherapy analyzed by flow cytometer. 

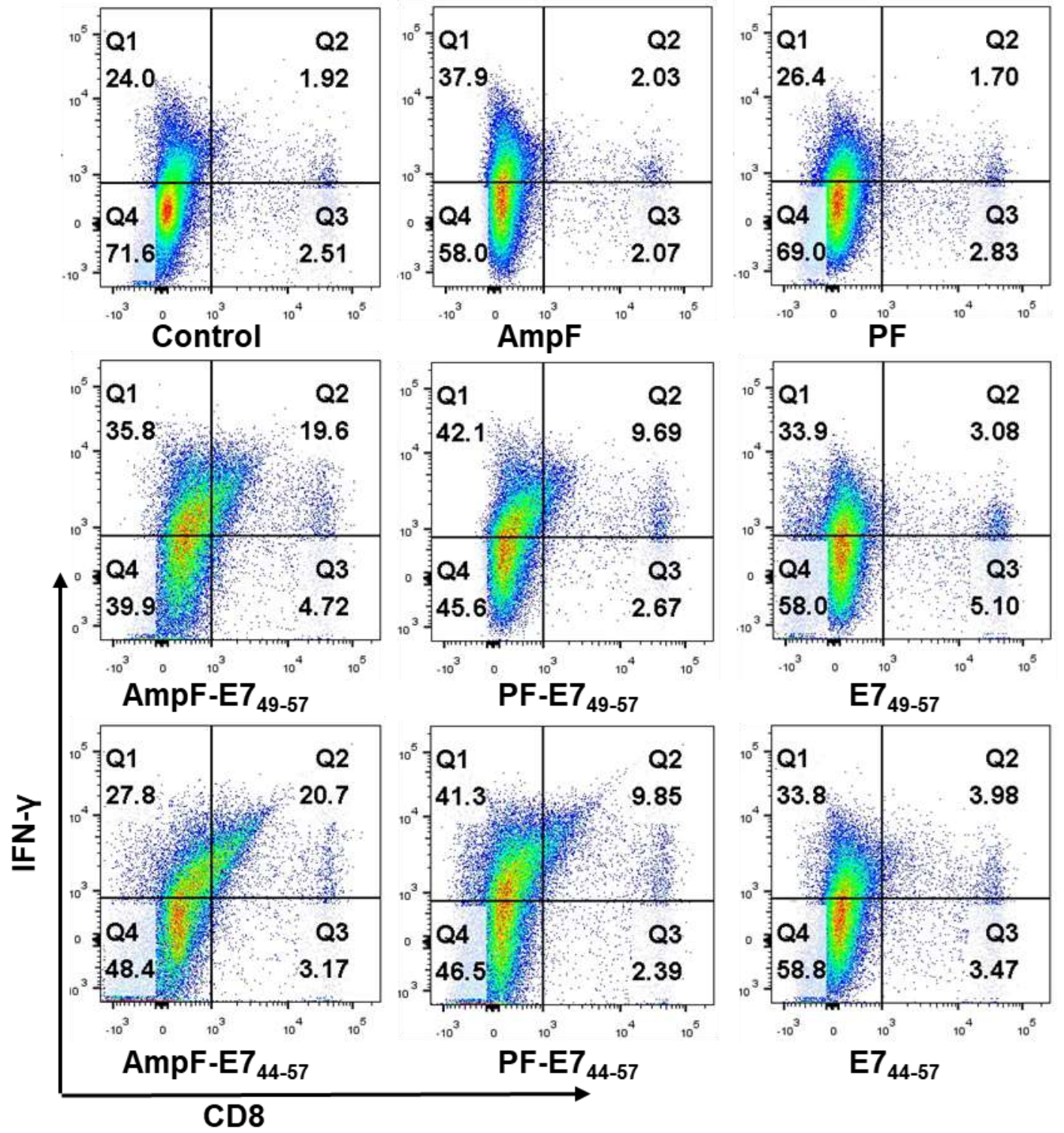

Figure S30. Representative FACS plots of $\mathrm{CD} 8^{+} \mathrm{IFN}-\gamma^{+} \mathrm{T}$ cells in the spleens dissected from mice at day 21 post-administration of PBS, pentapeptides AmpF and PF, peptides vaccines AmpF-E749-57, PF-E749-57, AmpF-E744-57, and PF-E744-57, peptides antigens E749-57 and E744-57 analyzed by flow cytometer. 


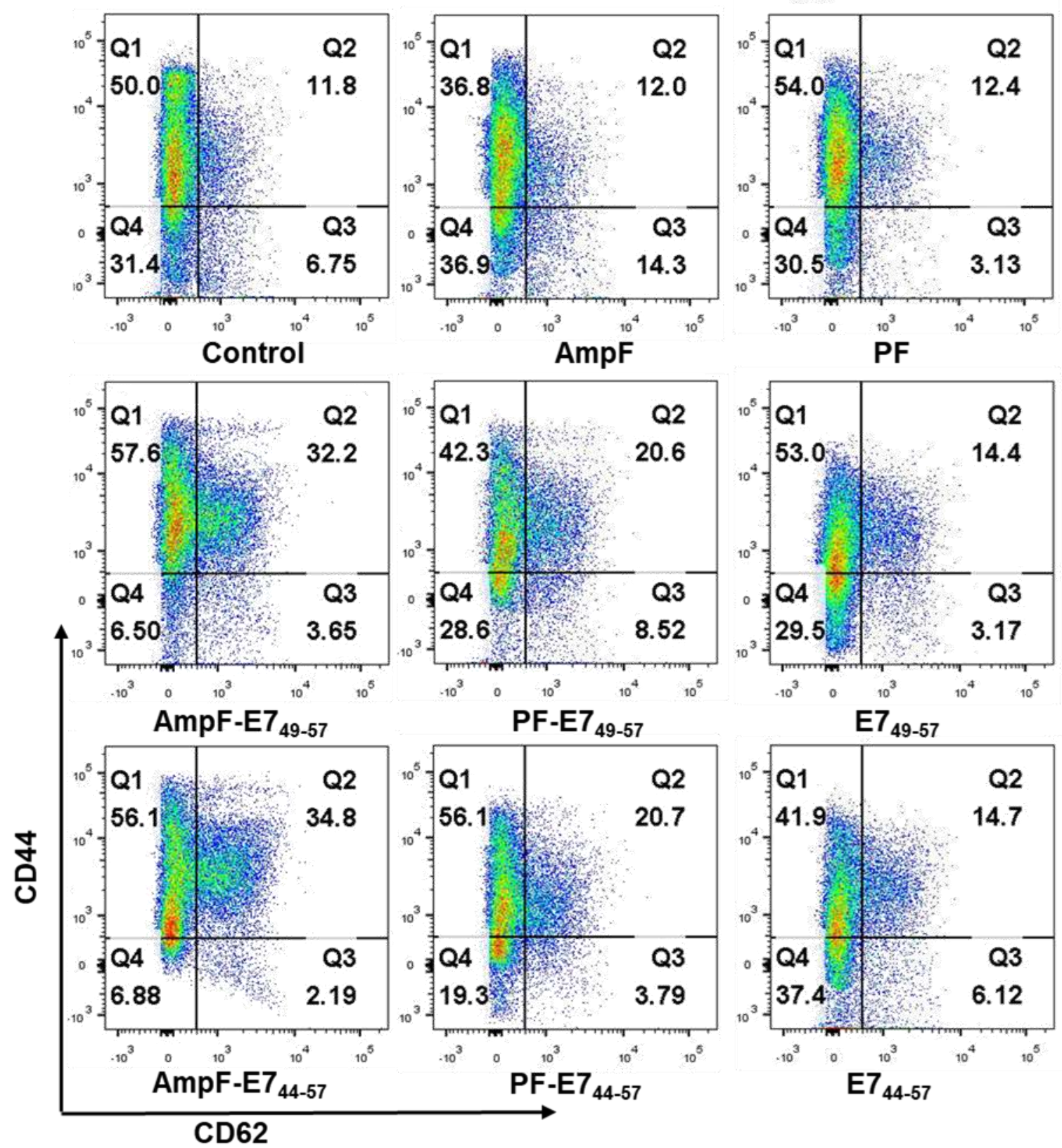

Figure S31. Representative FACS plots of $\mathrm{CD} 44^{\mathrm{Hi}} \mathrm{CD} 2 \mathrm{~L}^{+} \mathrm{T}$ cells cells in the $\mathrm{LNs}$ dissected from mice at day 21 post-administration of PBS, pentapeptides AmpF and PF, peptides vaccines AmpF-E749-57, PF-E749-57, AmpF-E744-57, and PF-E744-57, peptides antigens E749-57 and E744-57 analyzed by flow cytometer. 


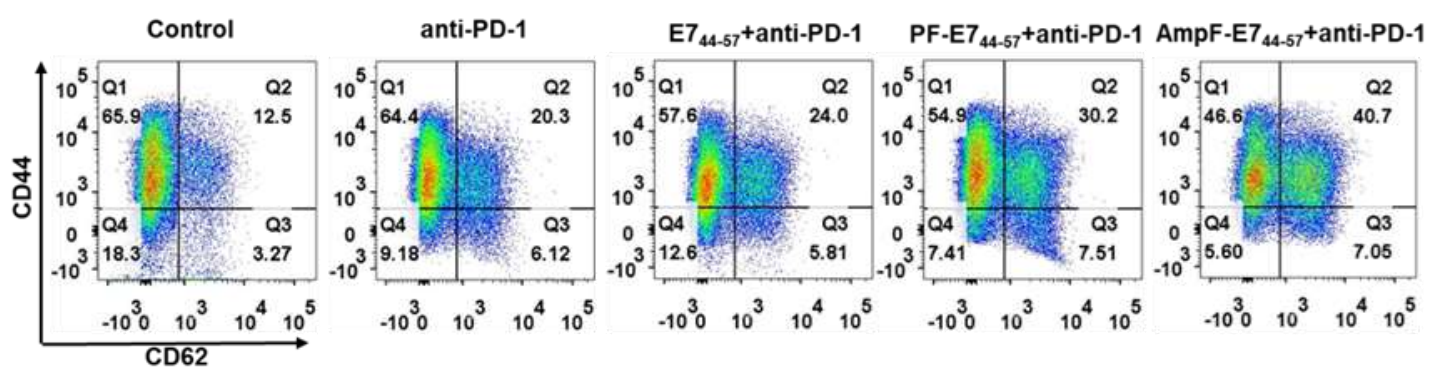

Figure S32 Representative FACS plots of CD44 ${ }^{\mathrm{Hi}} \mathrm{CD} 62 \mathrm{~L}^{+} \mathrm{T}$ cells in the LNs dissected from mice at day 21 post-administration of PBS, anti-PD-1, E7 ${ }_{44-57}+$ anti-PD-1, PFE744-57+anti-PD-1, and AmpF-E744-57+anti-PD-1 analyzed by flow cytometer.

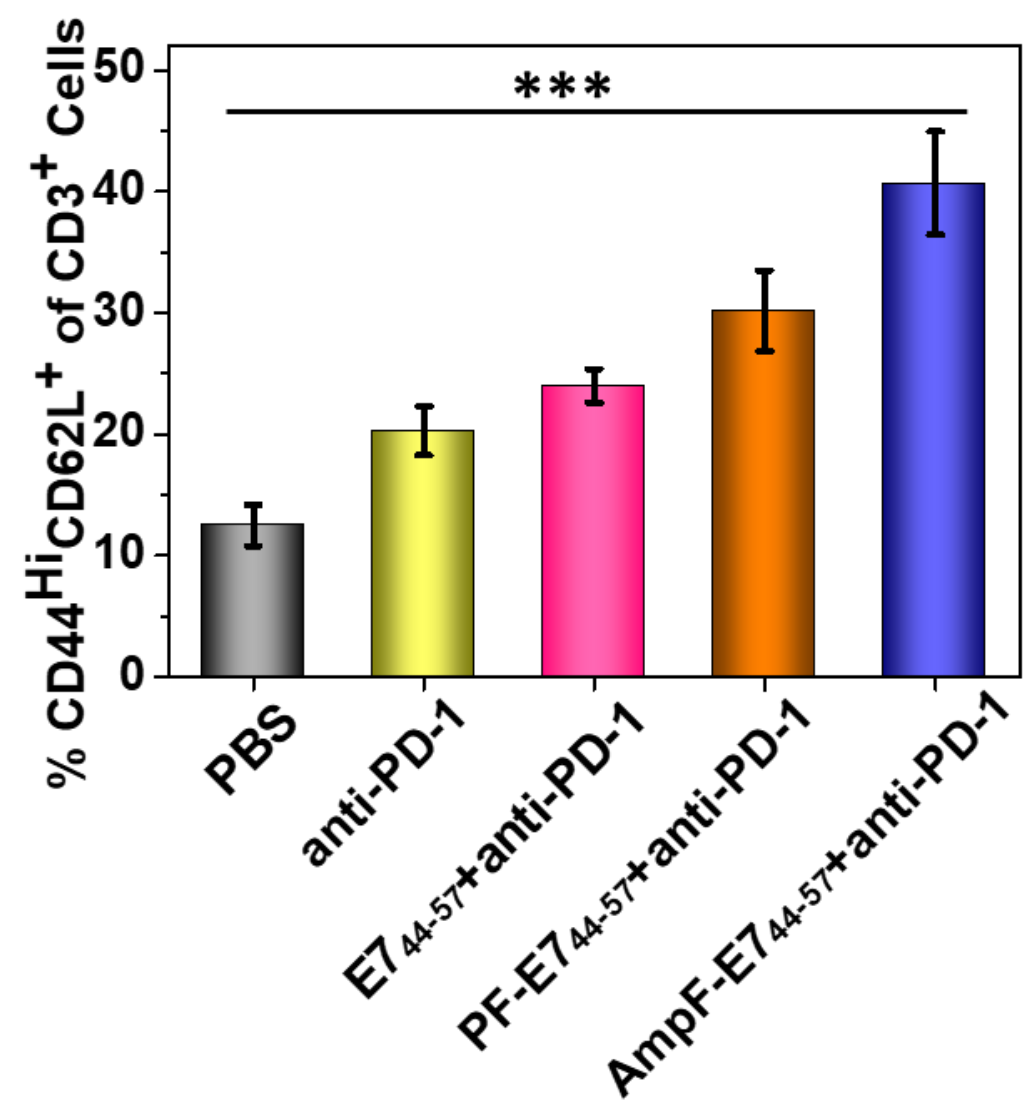

Figure S33 Quantification of TCM CD44 ${ }^{\mathrm{Hi}} \mathrm{CD} 62 \mathrm{~L}^{+}$cells in the LNs dissected from the mice administrated with PBS, anti-PD-1, E744-57 + anti-PD-1, PF-E7 ${ }_{44-57}+$ anti-PD-1, and AmpF-E744-57+anti-PD-1. 


\section{Hematoxylin-eosin and immunohistochemical staining}

Hematoxylin-eosin (H\&E) and immunohistochemical (IHC) staining assays were carried out for the dissected tissues including hearts, livers, spleens, lungs, kidneys and tumors from the treated mice. In the case of H\&E staining assays, a paraffin section process including fixation, dehydration, paraffin-embedding, cutting (thickness, $5 \mu \mathrm{m}$ ), and staining with hematoxylin and eosin of the tissues was performed. In the case of IHC staining assays, a frozen section process including fixation, cutting (thickness, $5 \mu \mathrm{m})$, blocking, anti-CD4 and CD8 antibody staining, and 3,3'-diaminobenzidine (DAB) staining of the tissues was performed. All the above staining tissues were imaged by an optical microscope (Olympus BX53, Germany).

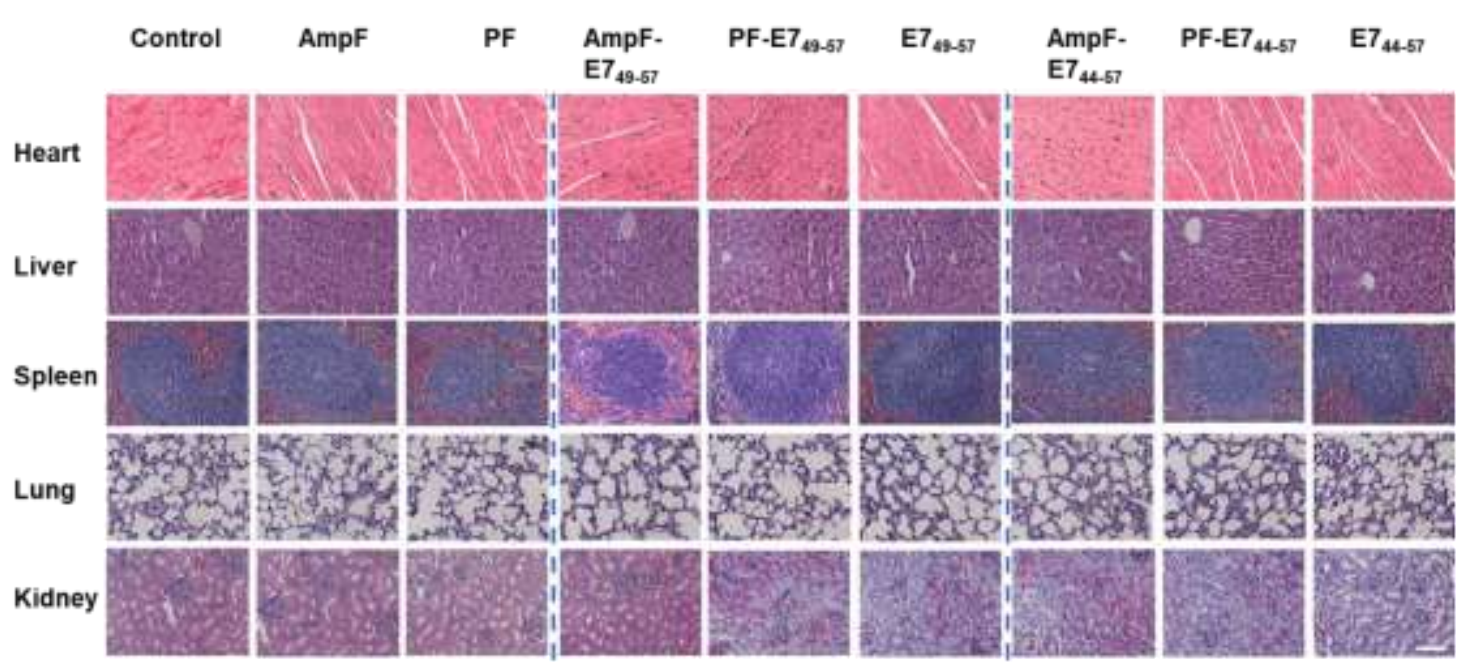

Figure S34. Representative H\&E section images of hearts, livers, spleens, lungs and

kidneys from the mice treated with PBS, pentapeptides AmpF and PF, peptides vaccines AmpF-E749-57, PF-E749-57, AmpF-E744-57, PF-E744-57, and peptide antigens E749-57 and

E744-57. Scale bar: $50 \mu \mathrm{m}$. 


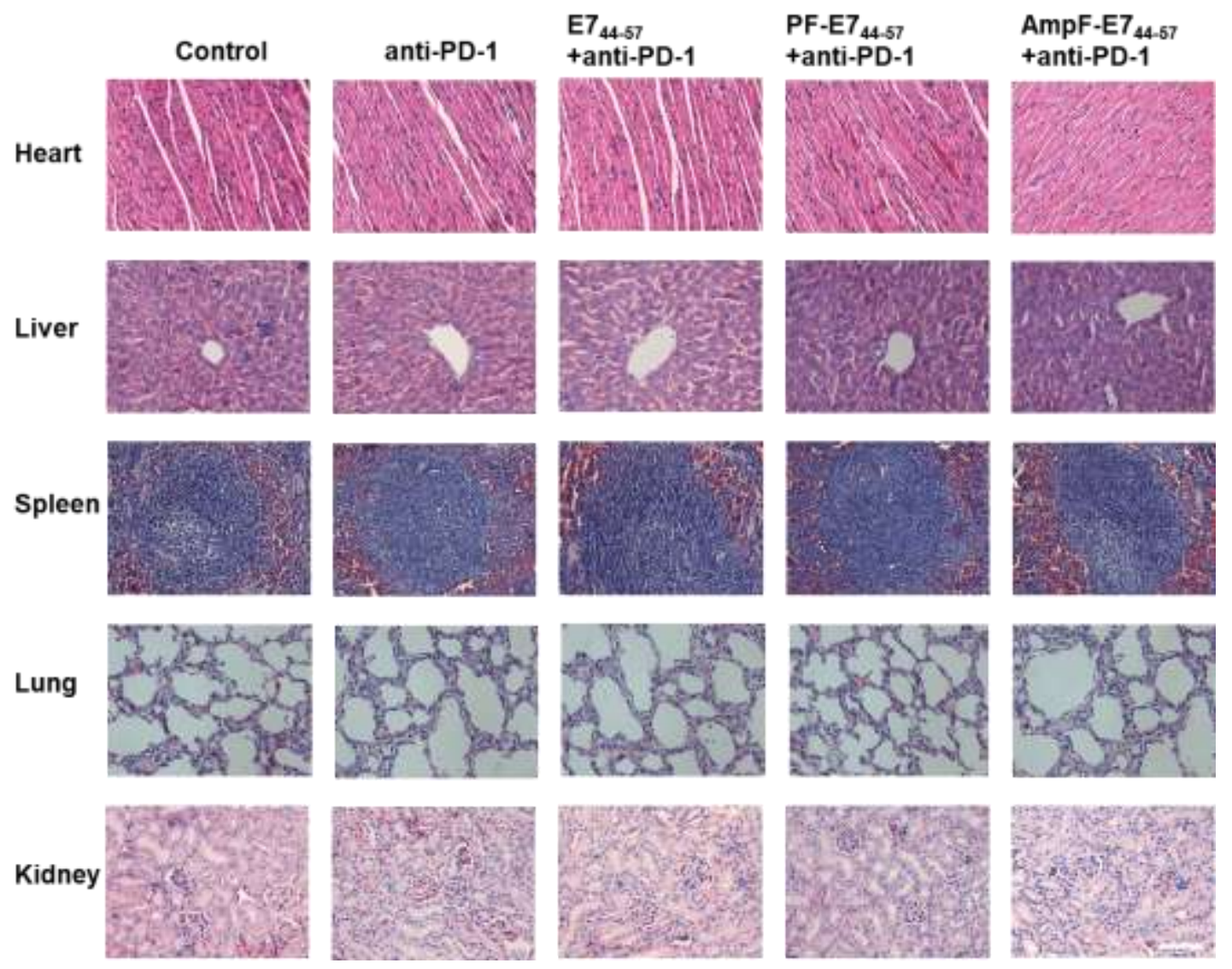

Figure S35. Representative H\&E section images of hearts, livers, spleens, lungs and kidneys of the mice after treatment with PBS, anti-PD-1, E744-57 +anti-PD-1, PF-E74457+anti-PD-1, and AmpF-E744-57+anti-PD-1. Scale bar: $50 \mu \mathrm{m}$. 